\title{
The impact of circulation patterns on regional transport pathways and air quality over Beijing and its surroundings
}

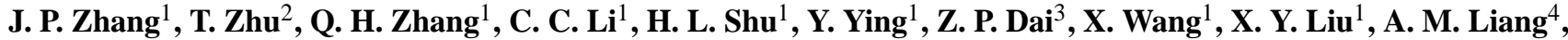 \\ H. X. Shen ${ }^{4}$, and B. Q. Yi ${ }^{5}$ \\ ${ }^{1}$ Department of Atmospheric and Oceanic Sciences, School of Physics, Peking University, Beijing, 100871, China \\ ${ }^{2}$ State Key Joint Laboratory of Environmental Simulation and Pollution Control, College of Environmental Sciences and \\ Engineering, Peking University, Beijing, 100871, China \\ ${ }^{3}$ Shenzhen Academy of Environmental Science, Shenzhen, 518001, China \\ ${ }^{4}$ Meteorological Center of North China Air Traffic Management Bureau of CAAC, Beijing, 100621, China \\ ${ }^{5}$ Department of Atmospheric Sciences, Texas A \& M University, College Station, TX 77845, USA
}

Correspondence to: Q. H. Zhang (qzhang@pku.edu.cn) and J. P. Zhang (zhangjp@pku.edu.cn)

Received: 6 November 2011 - Published in Atmos. Chem. Phys. Discuss.: 19 December 2011

Revised: 15 May 2012 - Accepted: 16 May 2012 - Published: 7 June 2012

\begin{abstract}
This study investigated the air pollution characteristics of synoptic-scale circulation in the Beijing megacity, and provided quantitative evaluation of the impacts of circulation patterns on air quality during the 2008 Beijing Summer Olympics. Nine weather circulation types (CTs) were objectively identified over the North China region during 2000-2009, using obliquely rotated T-mode principal component analysis (PCA). The resulting CTs were examined in relation to the local meteorology, regional transport pathways, and air quality parameters, respectively. The FLEXPART-WRF model was used to calculate 48-h backward plume trajectories for each CT. Each CT was characterized with distinct local meteorology and air mass origin. CT 1 (high pressure to the west with a strong pressure gradient) was characterized by a northwestern air mass origin, with the smallest local and southeasterly air mass sources, and CT 6 (high pressure to the northwest) had air mass sources mostly from the north and east. On the contrary, CTs 5, 8, and 9 (weak pressure field, high pressure to the east, and low pressure to the northwest, respectively) were characterized by southern and southeastern trajectories, which indicated a greater influence of high pollutant emission sources. In turn, poor air quality in Beijing (high loadings of $\mathrm{PM}_{10}, \mathrm{BC}, \mathrm{SO}_{2}, \mathrm{NO}_{2}, \mathrm{NO}_{\mathrm{x}}$, $\mathrm{O}_{3}$, AOD, and low visibility) was associated with these CTs. Good air quality in Beijing was associated with CTs 1 and 6 . The average visibilities (with $\pm 1 \sigma$ ) in Beijing
\end{abstract}

for CTs 1 and 6 during 2000-2009 were $18.5 \pm 8.3 \mathrm{~km}$ and $14.3 \pm 8.5 \mathrm{~km}$, respectively. In contrast, low visibility values of $6.0 \pm 3.5 \mathrm{~km}, 6.6 \pm 3.7 \mathrm{~km}$, and $6.7 \pm 3.6 \mathrm{~km}$ were found in CTs 5,8 , and 9, respectively. The mean concentrations of $\mathrm{PM}_{10}$ for CTs $1,6,5,8$, and 9 during 2005-2009 were $90.3 \pm 76.3 \mu \mathrm{g} \mathrm{m}^{-3}, 111.7 \pm 89.6 \mu \mathrm{g} \mathrm{m}^{-3}$, $\quad 173.4 \pm 105.8 \mu \mathrm{g} \mathrm{m}^{-3}, \quad 158.4 \pm 90.0 \mu \mathrm{g} \mathrm{m}^{-3}, \quad$ and $151.2 \pm 93.1 \mu \mathrm{g} \mathrm{m}^{-3}$, respectively.

Analysis of the relationship between circulation pattern and air quality during the emission control period suggests that CTs are the primary drivers of day-to-day variations in pollutant concentrations over Beijing and its vicinity. During the Olympics period, the frequency of CT 6 was twice that of the mean in August from 2000 to 2009. This CT had northerly transport pathways and favorable meteorological conditions (e.g. frequent precipitation) for clean air during the Olympics. Assuming that relationships between CTs and air quality parameters in the same season are fixed in different years, the relative contributions of synoptic circulation to decreases in $\mathrm{PM}_{10}, \mathrm{BC}, \mathrm{SO}_{2}, \mathrm{NO}_{2}, \mathrm{NO}_{\mathrm{x}}, \mathrm{CO}$, and horizontal light extinction during the Olympics were estimated as $19 \pm 14 \%, 18 \pm 13 \%, 41 \pm 36 \%, 12 \pm 7 \%, 10 \pm 5 \%$, $19 \pm 11 \%$, and $54 \pm 25 \%$, respectively. 


\section{Introduction}

Air pollution has become a major environmental problem in China as a consequence of industrialization and urbanization during years of rapid economic growth (Chan and Yao, 2008; Fang et al., 2009). Poor air quality can have adverse effects on human health, and air pollution levels greatly exceeding health-based standards have been frequently recorded in many major cities in China (J. Zhang et al., 2010), arousing much public concern. In particular, the urban air pollution in the North China Plain is much more serious than that in other areas (Chan and Yao, 2008). Policy makers in China now face the challenge of dealing with air pollution as a side effect of megacity urbanization. Accurate prediction and effective mitigation of air pollutant distributions are of vital importance.

Beijing, the capital of China, has experienced serious air pollution over the past $30 \mathrm{yr}$, characterized by historically high loadings of particulate matter and sulfur dioxide and recent increasing concentrations of ozone and nitrogen oxide (Wang et al., 2012; Chan and Yao, 2008). As the host of the 29th Summer Olympic Games, Beijing drew much attention for its air quality problems. To ensure good air quality during the Olympics and Paralympics, the Chinese government implemented a series of drastic measures to reduce air pollutant emissions in Beijing and the surrounding areas from 20 July to 20 September 2008 (M. Wang et al.,2009, 2011; S. Wang et al., 2010). Evaluation of the potential effects of these unprecedented control measures on air quality in and around Beijing provides valuable information for furthering both scientific understanding and future policy. Many studies documented a significant reduction in airborne pollutants on the basis of surface and satellite observations during the Olympics (Witte et al., 2009; Mijling, 2009; M. Wang et al., 2009; S. Wang et al., 2010; T. Wang et al., 2010). A few studies attempted to investigate the role of meteorology and anthropogenic emission restriction in the air quality improvement during the Olympics. Y. Wang et al. (2009) attributed $55 \%$ of the ozone decrease at a Beijing rural site (Miyun site) during the Olympics compared to the same period in 2006-2007 to meteorology. Q. H. Zhang et al. (2010) suggested that the decrease in relative humidity $(\mathrm{RH})$ during the Olympics compared to the same period in the previous $5 \mathrm{yr}$ contributed $24 \%$ to atmospheric visibility improvements. Using a coupled meteorology-chemistry model, Gao et al. (2011) concluded that meteorological conditions were as important as emission controls in reducing aerosol concentrations during the Olympics period. The advantageous weather conditions (e.g. prolonged rainfall and decreased temperature) were important for explaining the reduced pollutants during the Olympics, as described by $\mathrm{X}$. Zhang et al. (2009) and T. Wang et al. (2010). However, the dependence of the control effect on synoptic weather patterns has not yet been studied using a circulation-to-environment approach (Yarnal, 1993). The effects of emission control mea- sures must be evaluated under different meteorological conditions so that the relative contribution of reduced anthropogenic emissions to improved air quality can be calculated more accurately.

While urban air quality can vary in response to changes in pollutant emission and weather conditions, the emission of air pollutants also depends on meteorological conditions in some cases. For example, the energy consumption in cities would increase under heat wave conditions. However, the relationship between emission and weather conditions is not as important as the atmospheric dispersion, transport, and removal of pollutants. Understanding the relationship between air pollutant concentrations and the prevailing circulation at both synoptic and local scales is vital for air pollution forecasts.

Synoptic weather types can be identified by two approaches: air-mass and circulation-based classifications. The air-mass-based approach determines weather types from local values of meteorological variables (e.g. temperature, humidity, and wind speed). The circulation-based approach determines the circulation types (CTs) from sea level pressure (SLP), geopotential height, or wind fields defined for each time interval of the analysis on a regular grid (Huth et al., 2008). Because the meteorological variables that affect air quality are often closely interrelated and strongly modulated by the synoptic-scale circulation (e.g. the phases of cyclonic systems and anticyclones), the circulation-based classification approach is more suitable for determining synoptic weather types. Accordingly, the synoptic climatology method has been widely used to evaluate daily air quality variations (Kalkstein and Corrigan, 1986; Comrie and Yarnal, 1992; McGregor and Bamzelis, 1995; Shahgedanova et al., 1998). The synoptic approach to air pollution has the advantage of allowing consideration of many interrelated meteorological variables within an integrated framework (Jiang et al., 2005).

To evaluate the relationship between weather and air quality, we need ways to define different weather patterns. Circulation classification has become popular in climate and environmental study, particularly in mid- and high latitude regions where local weather conditions are dominantly driven by the day-to-day synoptic circulation variability (Jacobeit, 2010; Huth et al., 2008). However, few studies have addressed weather classification in Asia, particularly in China (Huth et al., 2008). Cheng et al. (2001) found that high ozone levels were associated with anticyclonic synoptic types and a tropical low pressure system moving northward closer to Taiwan. More recent studies (Chen et al., 2008; Wei et al., 2011) showed that the evolution and different sections of an anticyclonic system play an important role in controlling air quality. These studies of the dependence of air quality on the synoptic weather situation have been performed on a caseby-case basis over short periods, using subjective methods. A more general analysis method is needed to understand the impact of weather systems on local air quality. 
Here an objective weather classification approach was used to provide new insights into circulation patterns associated with air pollution over $10 \mathrm{yr}$. The impact of synoptic circulation on air quality during the 29th Summer Olympics was evaluated. The transport pathway characteristics of circulation types were obtained using a Lagrangian dispersion model driven by output data from a high-resolution mesoscale meteorological model. The data and methods used are presented in Sect. 2. Synoptic circulation types and their relation to local meteorological conditions and transport pathways are described in Sect. 3. The air quality over Beijing under each circulation type is analyzed in Sect. 4. In Sect. 5, the effectiveness of the synoptic circulation in reducing air quality during the Beijing Olympics is discussed, and in Sect. 6, the conclusions, discussions, and future researches are presented.

\section{Data and methodology}

\subsection{Meteorological data}

Gridded daily surface level pressure (SLP) data were used to determine the prevailing circulation types at the regional scale. The SLP data were derived from the National Centers for Environmental Prediction (NCEP)/National Center for Atmospheric Research (NCAR) final global forecase sytem (FNL) reanalysis dataset $\left(1^{\circ}\right.$ horizontal resolution) for the period 2000-2009. The region was defined as an area from 32 to $49^{\circ} \mathrm{N}$ and 103 to $129^{\circ} \mathrm{E}$. The grid numbers $(27 \times 18)$ has the same size as to that of "Western Mediterranean" domain in Philipp et al. (2010). The NCEP/NCAR FNL SLP reanalysis data are available for 00:00, 06:00, 12:00, and 18:00 UTC. In this study, 00:00 UTC (08:00 LT) was chosen to determine daily circulation type because the radiosonde coverage was more comprehensive at this time. The more radiosonde data assimilated in NCEP global model, the more improvement in the accuracy of simulated meteorological fields both at upper-level and surface.

The local meteorological data used in this study include all available hourly observational parameters (temperature, pressure, dew point temperature, $\mathrm{RH}$, cloud fraction, visibility, and wind speed and direction) during 2000-2009 from the Automated Surface Observing System (ASOS) at Beijing Capital International Airport (BCIA). These data were provided by the information center of BCIA after quality control. Visibility and clouds were observed and recorded manually once per hour. Detailed weather phenomena records and daily precipitation from 2000-2009 were also used in this study. Data from BCIA were used as a proxy for weather conditions in Beijing because this station measured more weather parameters and had a longer period of available integral records (no missing data) than other stations in Beijing. The light extinction coefficients (Table 2) were calculated from Koschmieder's formula, $\sigma_{\text {ext }}=3.912 / V$, where $\sigma_{\text {ext }}$ is the extinction coefficient and $V$ is the visibility. This study also used meteorological data observed by the ASOS on the roof of the Physics Building of Peking University (PKU site); the data used from this site included hourly observations of RH and precipitation during 2005-2009.

\subsection{Air pollutants measurements}

The measured air quality data used in this study included particulate matter of diameter less than $10 \mu \mathrm{m}$ $\left(\mathrm{PM}_{10}\right)$, black carbon (BC), $\mathrm{O}_{3}, \mathrm{SO}_{2}, \mathrm{NO}_{2}$, nitrogen oxides $\left(\mathrm{NO}_{\mathrm{x}}=\mathrm{NO}+\mathrm{NO}_{2}\right), \mathrm{CO}$, and the aerosol optical depth (AOD). The $\mathrm{PM}_{10}$ was measured with a tapered element oscillating microbalance (TEOM 1400a, Rupprecht and Patashnick Co., Inc.) from 2005 to 2009. The instrument was installed at the PKU site $\left(39.99^{\circ} \mathrm{N}, 116.31^{\circ} \mathrm{E}\right.$, shown in Fig. 1b), which is approximately $26 \mathrm{~m}$ above the ground. The sampling interval was set to $5 \mathrm{~min}$.

An AE16 aethalometer (Magee Scientific Inc., USA) was used to measure the BC concentration from January 2005 to December 2009. This instrument was installed in a room built on the roof of PKU Physics Building. The instrument operated at a near-infrared wavelength of $880 \mathrm{~nm}$. He et al. (2009) have provided a more detailed description of the instrument and measurements. Data were recorded every 5 min. Invalid $\mathrm{BC}$ and $\mathrm{PM}_{10}$ data resulting from instrumental problems or precipitation were removed. Moreover, the sulfate in $\mathrm{PM}_{1}$ at PKU site during the period 24 July to 1 September 2008 was also used. The instruments and measurements were described in detail by Huang et al. (2010).

The gaseous pollutant $\left(\mathrm{O}_{3}, \mathrm{SO}_{2}, \mathrm{NO}_{2}, \mathrm{NO}_{\mathrm{x}}\right.$, and $\left.\mathrm{CO}\right) \mathrm{ob}-$ servations were provided by the CARE-Beijing campaign sites in Beijing during the period from August 2006 to October 2008. The instruments and measurements have been described in several papers on CARE-Beijing Campaigns (e.g. Chou et al., 2009, 2011). The hourly $\mathrm{O}_{3}, \mathrm{SO}_{2}, \mathrm{NO}_{2}, \mathrm{NO}_{\mathrm{x}}$, and $\mathrm{CO}$ observations at PKU station were used in this study. The PKU station $\left(39.99^{\circ} \mathrm{N}, 116.31^{\circ} \mathrm{E}\right)$ was in urban Beijing (denoted by a black dot) in Fig. 1b, on the top of a sixstorey building on the campus of PKU. This urban site is in the northwest of Beijing city, about 500 m north of the fourth ring road, $5 \mathrm{~km}$ west of the Olympic Park, and $10 \mathrm{~km}$ from the center of Beijing. The PKU campus was a primarily residential and commercial area without industrial sources. Wehner et al. (2008) suggested a good agreement of the $\mathrm{PM}_{2.5}$ mass and chemical composition in 1999-2002 between the PKU site and a downtown site. Therefore, PKU site was assumed to be representative of a typical urban environment in Beijing (Cheng et al., 2008; Wehner et al., 2008; B. Wang et al., 2010; Chou et al., 2011). Even though the measurements from one site may not reflect the average air pollution levels in Beijing, the daily temporal variation trends of air pollutants at this site are similar to those from whole Beijing, hence the association of the variation with circulation pattern can be representative for the whole city. 


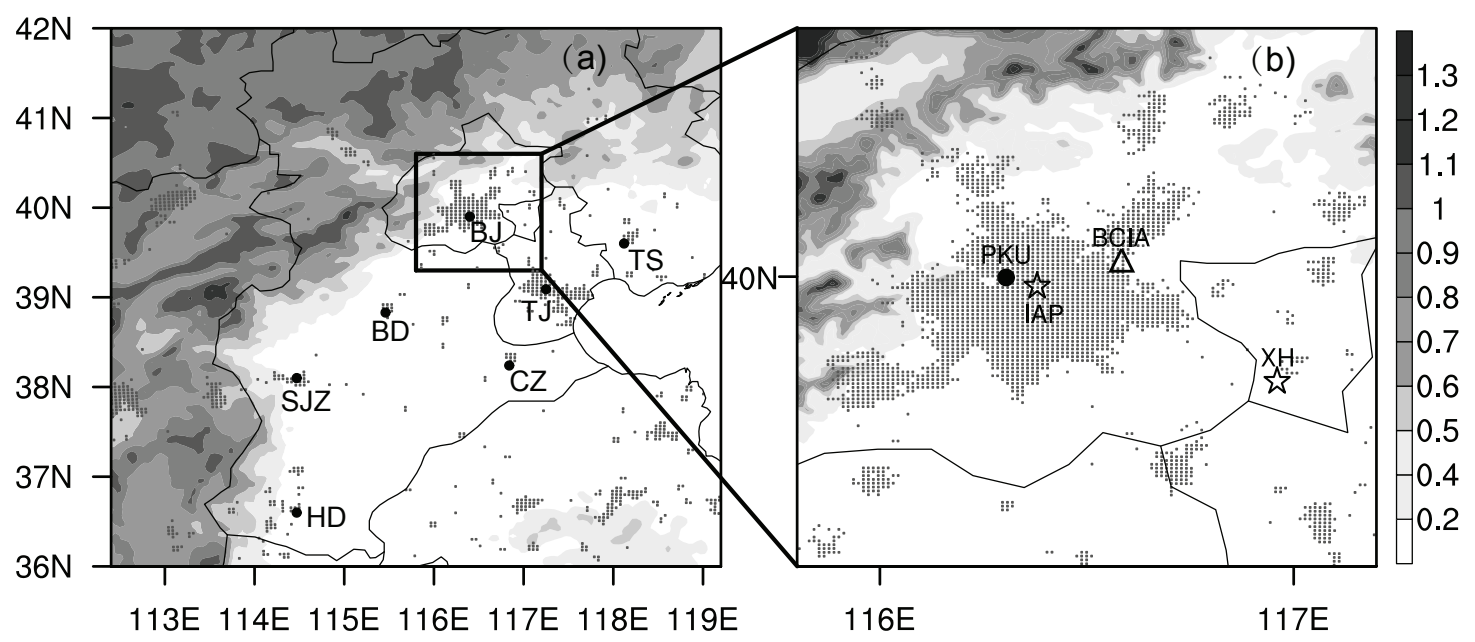

Fig. 1. Terrain height $(\mathrm{km})$ and urban distribution (dotted region) around Beijing. (a) Black dots represent major cities in the North China Plain. BJ, TJ, BD, SJZ, HD, CZ, and TS represent Beijing, Tianjin, Baoding, Shijiazhuang, Handan, Cangzhou, and Tangshan, respectively. (b) Loci of the BCIA, PKU, AERONET Beijing (IAP), and Xianghe (XH) sites.

The Aerosol Robotic Network (AERONET) program is a global ground-based aerosol monitor network that was initiated in the 1990s and has expanded rapidly across the world. The level-2.0 quality-assured AOD data of the AERONET Beijing and Xianghe (XH) sites from March 2001 to December 2009 were downloaded from the AERONET data archive (http://aeronet.gsfc.nasa.gov). All data were well calibrated (Holben et al., 1998), automatically cloud screened (Smirnov et al., 2000), and manually inspected. The uncertainty of AOD was 0.01 0.02 (Eck et al.,1999). Data from sun photometers (Cimel Electronique, France) at two sites ( $30 \mathrm{~m}$ above the ground) were used: (1) the Institute of Atmospheric Physics site (IAP, $39.98^{\circ} \mathrm{N}, 116.38^{\circ} \mathrm{E}$ ), Chinese Academy of Sciences, which is located in the densely populated urban area of Beijing, and (2) the $\mathrm{XH}$ site $\left(116.96^{\circ} \mathrm{E}, 39.75^{\circ} \mathrm{N}\right)$, which is located approximately $60 \mathrm{~km}$ east/southeast of downtown Beijing (shown in Fig. $1 \mathrm{~b}$ as hollow stars). The AERONET data included AOD values recorded at 15 -min intervals in seven spectral bands (340, $380,440,500,675,870$, and $1020 \mathrm{~nm}$ ). Detailed descriptions of the sites, instrument and measurement methods and quality control procedure were given in several references (Holben et al., 1998; Smirnov et al., 2000; Xia et al., 2006; $\mathrm{Li}$ et al., 2009). The clear-sky AOD at $500 \mathrm{~nm}$ was used in this study, and interpolation was made to get sufficient AERONET AOD data samples for classification analysis. Since there are many missing measurements at the wavelengths of $500 \mathrm{~nm}$, these values have been interpolated from the values at 440 and $675 \mathrm{~nm}$, assuming the log-linearity in the range (Vucetic et al., 2008). There are 1849 and 1232 valid daily data at Beijing and XiangHe sites (shown in Supplement Fig. S5), respectively.

\subsection{Satellite data}

The AOD data from the Moderate Resolution Imaging Spectroradiometer (MODIS) are widely used to investigate the spatial distribution of tropospheric aerosols (e.g. Li et al., 2005). The standard Level-2 products of aerosols released by NASA have been assured in high quality (e.g. strict cloud masking), and validated widely over the global in numerous literatures (Kaufman and Tanré, 1998; Chu et al., 2003; Engel-Cox et al., 2004; Levy et al., 2005; He et al., 2010). The AOD data (Collection 5) of MODIS Level 2 products over land $(10-\mathrm{km}$ resolution at the nadir) from Terra and Aqua satellites were averaged for each weather type during the period from February 2000 to December 2009. For each circulation type, the mean AOD (at $550 \mathrm{~nm}$ wavelength) over Beijing $\left(39.5-40.4^{\circ} \mathrm{N}, 115.8-116.7^{\circ} \mathrm{E}\right)$ was calculated.

\subsection{Circulation classification}

There are currently five widely used circulation classification techniques: the correlation method (Lund, 1963), cluster analysis (Brinkmann, 1999; Cheng and Wallace, 1993), principal component analysis (PCA) (Richman, 1981; Huth, 2000, 1993), fuzzy method (Bardossy et al., 1995), and nonlinear methods (e.g. neural network) (Cavazos, 2000; Hewitson and Crane, 2002). For classification of circulation patterns, it was suggested that a T-mode should be applied to the PCA method (Huth et al., 2008; Huth, 1996a). This means that grid point values are organized in rows and cases (time series) in columns for the input data matrix (Compagnucci and Richman, 2008). Huth (1996b) and Huth et al. (2008) compared the five classification methods and proposed that the performance of the T-mode PCA is best in terms of its 
reproduction of predefined types, its temporal and spatial stability, and its less dependence on pre-set parameters.

Richman (1981) first proposed PCA as a tool for circulation classification. The potential use of PCA for classification purposes has been discussed and improved in detail (Gong and Richman, 1995; Huth, 1996a, b; Compagnucci and Richman, 2008). T-mode PCA has been used to study general circulation models (Huth, 2000), climate change (Müller et al., 2003), and air pollution climatology (Jiang et al., 2005. In this study, obliquely rotated T-mode PCA was used to identify the dominant circulation types over the North China region. We used the classification software developed within the framework of COST action 733 (http://www.cost733.org) (Huth et al., 2008; Philipp et al., 2010). The T-mode PCA was performed using procedures similar to those of Huth (2000). An oblique rotation is applied on the results of the PCA (Bernaards and Jennrich, 2005). A detailed description of the procedure has been reported by Philipp et al. (2010).

\subsection{Model calculations}

\subsubsection{Mesoscale meteorological model simulations}

The meteorological fields were computed using the Weather Research and Forecasting (WRF) model version 3.1.1. The model was configured with three two-way nested domains. The grid dimensions were $101 \times 101,121 \times 121$, and $221 \times 221$, with horizontal resolutions of $36 \mathrm{~km}, 12 \mathrm{~km}$, and $4 \mathrm{~km}$, for domains 1, 2, and 3, respectively (Supplement Fig. S1). All domains had 35 unevenly spaced terrainfollowing sigma levels, with the maximum resolution in the boundary layer and the model top at $50 \mathrm{hPa}$. The NCEP FNL reanalysis data $\left(1^{\circ}\right.$ horizontal resolution) and Global Telecommunications System (GTS) data were used to provide the initial and boundary conditions for model simulations. MODIS high resolution satellite remote sensing data (e.g. MODIS land use; Fig. 1) were used to initialize the parameters for the Noah land surface model (Chen et al., 2006). The model physics options were as follows: the MellorYamada-Janjić boundary layer scheme (Janjić, 2001), the WSM3 microphysics scheme (Hong et al., 2004), the rapid radiation transfer model longwave scheme (Mlawer et al., 1997), and the Dudhia shortwave scheme (Dudhia, 1989) for each domain. The Kain-Fritsch cumulus parameterization (new Eta) scheme (Kain, 2004) was used only for domains 1 and 2. Daily meteorological conditions from June 2008 to May 2009 were simulated by conducting a 36-h run from 00:00 UTC each day. Each 12-36-h period (12:00 UTC to 12:00 UTC the next day), at intervals of $30 \mathrm{~min}$, was collected to form the final output. Because the skill of LimitedArea (mesoscale) Models (LAMs) decreases very rapidly with time, the re-initialization by subdividing a long-term continuous integration into short ones has succeeded to mitigate the problem of systematic error growth in long integrations (Lo et al., 2008). This sequence of short runs with many re-initializations has been shown to outperform longterm continuous simulations with only one initialization (Pan et al., 1999; Žagar et al., 2006; Lo et al., 2008), and is becoming widely adopted (Žagar et al., 2006; Jiménez et al., 2010, 2012).

The nudging (or Newtonian relaxation) scheme could be another choice for long-term continuous simulations. However, the nudging approach may have some significant negative side-effects for this study. For the purpose of dynamical downscaling, we hypothesize that such utilization in the LAM can generate realistic regional structures that can't be resolved by the coarse-resolution forcing data. Beijing and its vicinity do have complex topography and land uses, and accordingly complicated air circulations. When the nudging is performed, the simulated state (realistic mesoscale structure) is forced to keep close to the driving state at coarseresolution NCEP data (unrealistic state). A big difference in solution between our LAM and the global model tends to result in the systematic error. The nudging-performed time points can also potentially cause unrealistic simulated structure, thermo-dynamical imbalance and gaps originated from different data. Therefore, we used the re-initialization approach. Since the mesoscale meteorological model has high skill in $36 \mathrm{~h}$ forecasting, the frequent re-initialization method (just 1 day interval) was utilized to improve the accuracy of the meteorological fields and to limit the gaps at the joint points. The gaps in the time series of the simulated meteorological parameters (wind direction and speed, temperature, relative humidity and column integrated water vapor) are not significant (shown in Figs. S2-4 in the Supplement).

The simulations with high resolution both in time and space by a mesoscale meteorological model are capable of well resolving regional mesoscale circulations (e.g. land-sea breeze; mountain-valley wind; urban heat island circulation) and significantly improving the accuracy of trajectory calculations over the region with a complex topography (Kahl and Samson 1986; Pagano et al., 2010). The WRF model outputs were compared with the in-situ and sounding measurements to evaluate its performance. The simulated meteorological variables (temperature, relative humidity and wind) at surface were generally in good agreement with the observations at BCIA although some difference remains (shown in Supplement Figs. S2-4). The mean errors of simulated surface temperature, $\mathrm{RH}$ and wind speed at the three stations were $1.4^{\circ} \mathrm{C}, 7.2 \%$, and $1.3 \mathrm{~ms}^{-1}$, respectively. The mean error of integrated precipitable water vapor was $3.6 \mathrm{~mm}$ in August. The averaged errors of temperature, relative humidity and wind speed at upper levels $(925,850,700,500$ and $300 \mathrm{hPa})$ were $0.64{ }^{\circ} \mathrm{C}, 8.3 \%$, and $2.9 \mathrm{~ms}^{-1}$, respectively, and the corresponding correlation coefficients were $0.97,0.91$ and 0.95 , respectively. 

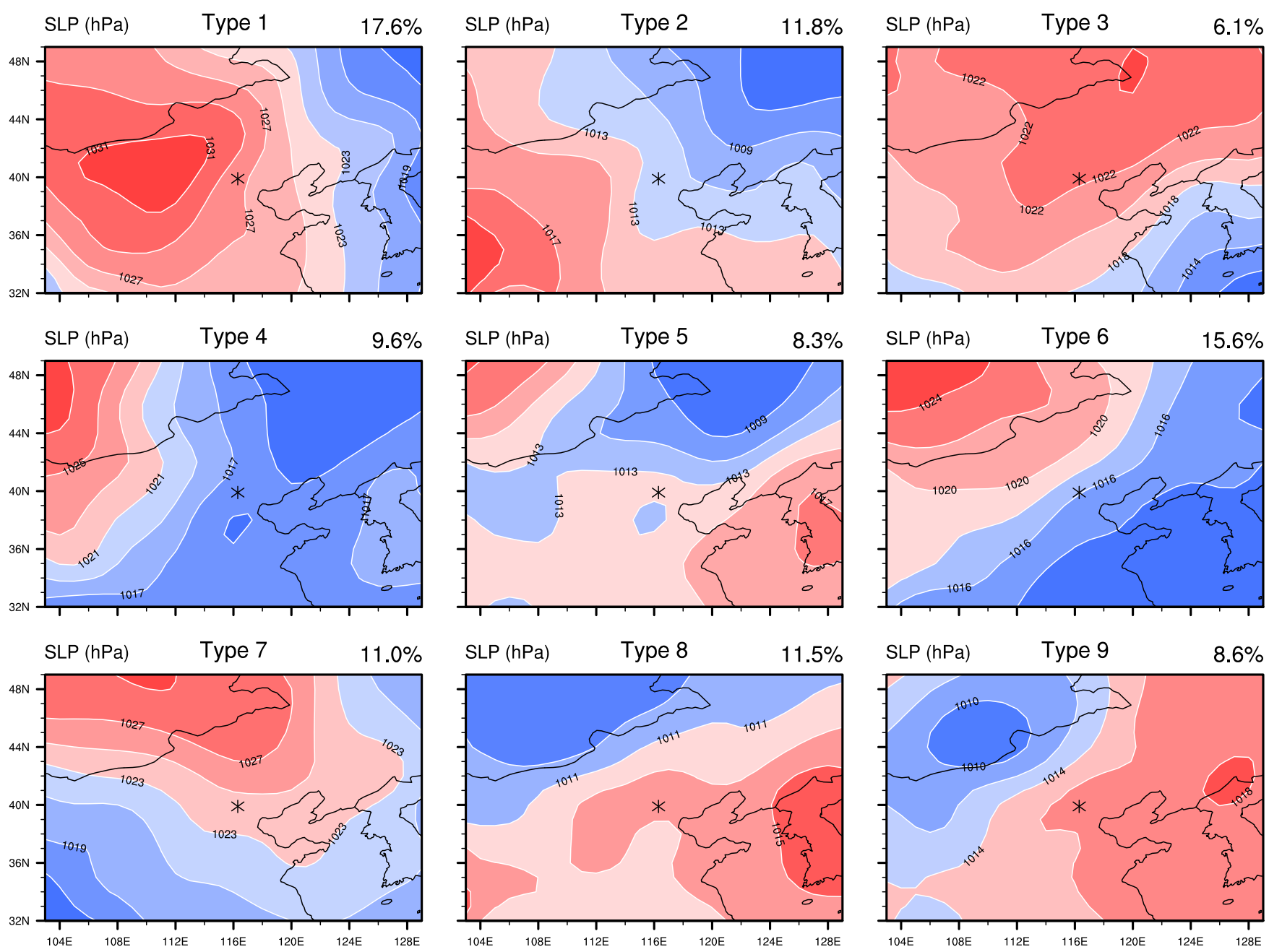

Fig. 2. Mean sea level pressure (SLP) patterns and frequency of occurrence (right upper number) for each circulation type during the period 2000 to 2009. The asterisk represents the location of Beijing.

\subsubsection{Lagrangian dispersion model calculations}

A Lagrangian dispersion model for particle transport and diffusion simulation, FLEXPART version 6.2 (Stohl et al., 1998, 2005; Fast and Easter, 2006), was used to determine the origin and transport pathways of the air mass arriving in Beijing. FLEXPART simulates the transport and dispersion of tracers by calculating the trajectories of multitudinous particles, which are termed plume (cloud) trajectories. In the model planetary boundary layer (PBL), turbulence is parameterized by solving the Langevin equation, and convection is parameterized using the Zivkovic Rothman scheme (Stohl et al., 2005). Because subgrid-scale flux exchanges and boundary layer eddies can affect dispersion simulations on local and synoptic scales (Pagano et al., 2010), we used high-resolution WRF simulation domains 2 and 3 outputs, as described in the previous subsection, as the input ambient meteorological conditions for the FLEXPART model.
The turbulence, convection and boundary layer height were calculated along the trajectories using the WRF output data. Backward integration was performed hourly during the period from June 2008 to May 2009. For each integration, 1000 stochastic particles were released initially from within a box of $4 \times 4 \mathrm{~km}^{2}$ horizontal extent and 0-50 m vertical height (de Foy et al., 2009, 2011; Aiken et al., 2010) centered on the PKU site. In total 8760000 particles were released over the 1 -yr period. Particle trajectories were integrated for $48 \mathrm{~h}$ in backward mode, and the particle locations were output every $30 \mathrm{~min}$ for analysis. The $48 \mathrm{~h}$ length of the backward trajectories was chosen as a trade-off in order to sample adequately the history of the air masses over the region of interest, while reducing the trajectories error (Stohl, 1998; Kahl and Samson, 1986). 


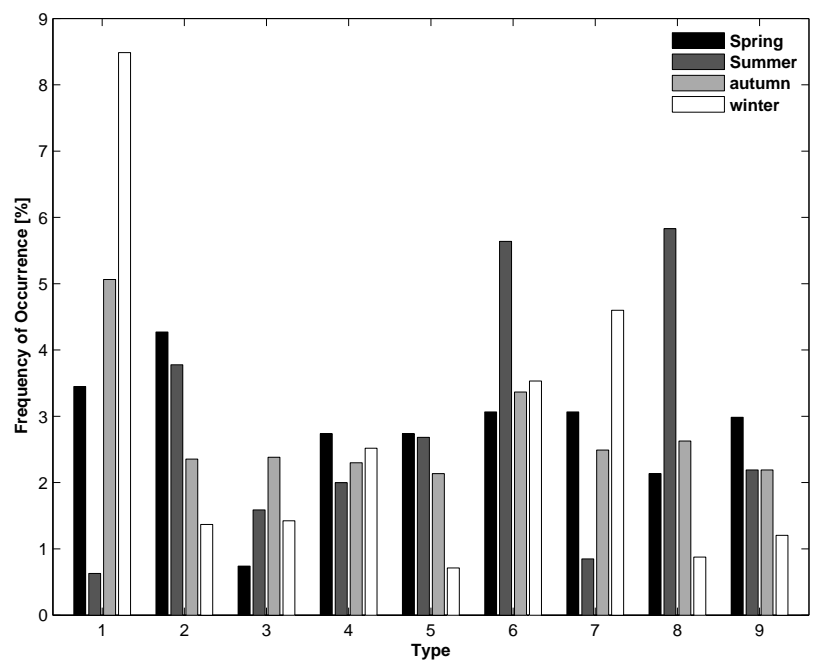

Fig. 3. Seasonal variation of frequency of the nine circulation types during 2000-2009.

\subsection{Residence time analysis of back trajectories}

To visualize the plume trajectories, the footprints (i.e., emission sensitivity) of 48-h backward trajectories were calculated. Footprints in this context refer to the total residence times of released particles. Residence times were calculated following Ashbaugh et al. (1985) by counting the accumulated number of particles during the integration within each cell of a $0.05^{\circ}$ (about $5 \mathrm{~km}$ ) grid over the interested region. The "residence time" thus corresponded to the time that air pollutants spent in each grid cell before arriving at the site. A few examples for footprint map of 48-h plume backward trajectories released at a specific time from PKU site has been shown in figure $\mathrm{S} 6$ of the supplement. Various transport patterns could well be described by these footprints analyses, especially for recirculation and low-level wind convergence phenomena, which could not be resolved via low-resolution meteorological data or simple back trajectory calculations.

\section{Circulation patterns and related meteorological conditions}

Nine prevailing circulation patterns were obtained over the North China region during the 2000-2009 period using the obliquely rotated T-mode PCA. The composite mean SLP maps for the resulting circulation types are shown in Fig. 2, along with their frequencies of occurrence. According to the flow regimes and the positions of the main synoptic centers, the circulation types were identified as (1) high pressure to west with strong pressure gradient $(\mathrm{WH}+)$; (2) high pressure to west-south (WSH); (3) high pressure to northeast (NEH); (4) low (L); (5) unique (U; i.e. weak pressure field); (6) high pressure to northwest (NWH); (7) high pressure to north $(\mathrm{NH}) ;(8)$ high pressure to east (EH, rear of anticyclone); and
(9) low pressure to northwest (NWL). The most frequent circulation types were $1(\mathrm{WH}+, 17.6 \%)$ and $6(\mathrm{NWH}, 15.6 \%)$. These two types accounted for $33.2 \%$ of the total and represented prevailing northwesterly to northeasterly airflows over Beijing. Circulation types characterized by low pressure gradients (types 5 and 8, i.e. $\mathrm{U}$ and $\mathrm{EH}$ ) accounted for $19.8 \%$. Under these weather conditions, the regional circulation was dominated by the local thermal gradient and topographic effects. Type 4 (L, $9.6 \%$ ) was dominated by low pressure systems. Overall, cyclonic systems influenced Beijing less frequently than anticyclone systems.

Figure 3 presents the seasonal variation of circulation types. Beijing is located in the Mid-Latitude Eastern Eurasian continent, where monsoon circulation is prevalent. The regional climate is characterized by long winters and summers and short springs and autumns (Sun et al., 2010). Baroclinic waves are most frequent in winter and spring. The subtropical high over the Western Pacific greatly affects the North China Plain in summer and sometimes in autumn. Circulation types 4 and 6 could be associated with the different phases (or positions) of eastward-shifting low pressure systems from baroclinic waves over North China. In summer, circulation types 8,9 , and 5 could be frequently associated with the subtropical high. When the subtropical high dominates over the east of Beijing, fast-moving baroclinic waves are blocked far to the north of the city, most of the area is under the control of a southerly maritime airstream, and the temperature and humidity are high. Types 1 and 7 occur most frequently in winter, while types 6 and 8 occur more in summer.

The prevalent local meteorological conditions associated with a specific circulation type play an important role in the air pollution. Some basic characteristics of the average meteorological variables for the types during 2000-2009 can be inferred from Table 1 and Fig. 4. The mean temperature for type $1\left(4.7^{\circ} \mathrm{C}\right)$ and $7\left(6.6^{\circ} \mathrm{C}\right)$ were typical winter values. Type 8 , which was dominant in summer, was the warmest and most humid of the nine circulation types. Types 1 and 6 were dominated by northerly and northwesterly airflows, while types 5, 8, and 9 had dominant southwesterly winds. The calm wind frequencies of type 1 and type 6 were the lowest among all types (Fig. 4). The composite mean SLP map for types 1 and 6 exhibited a relatively stronger west-to-east pressure gradient, which resulted in the highest wind speed among the nine circulation types. In contrast, the mean SLP of types 5,8 , and 9 all displayed a relatively weak pressure gradient and low wind speed, which in turn resulted in stagnant air parcels and limited dispersal of pollutants. The student's t-test revealed that meteorological parameters among the different circulation types generally had statistical differences at a 0.05 level (Table S1).

The daily maximum PBL height at BCIA was calculated from the WRF model outputs with 4-km horizontal resolution for $1 \mathrm{yr}$ (June 2008-May 2009; Table 1). Types 2 and 6 exhibited higher daily maximum PBL heights than other 

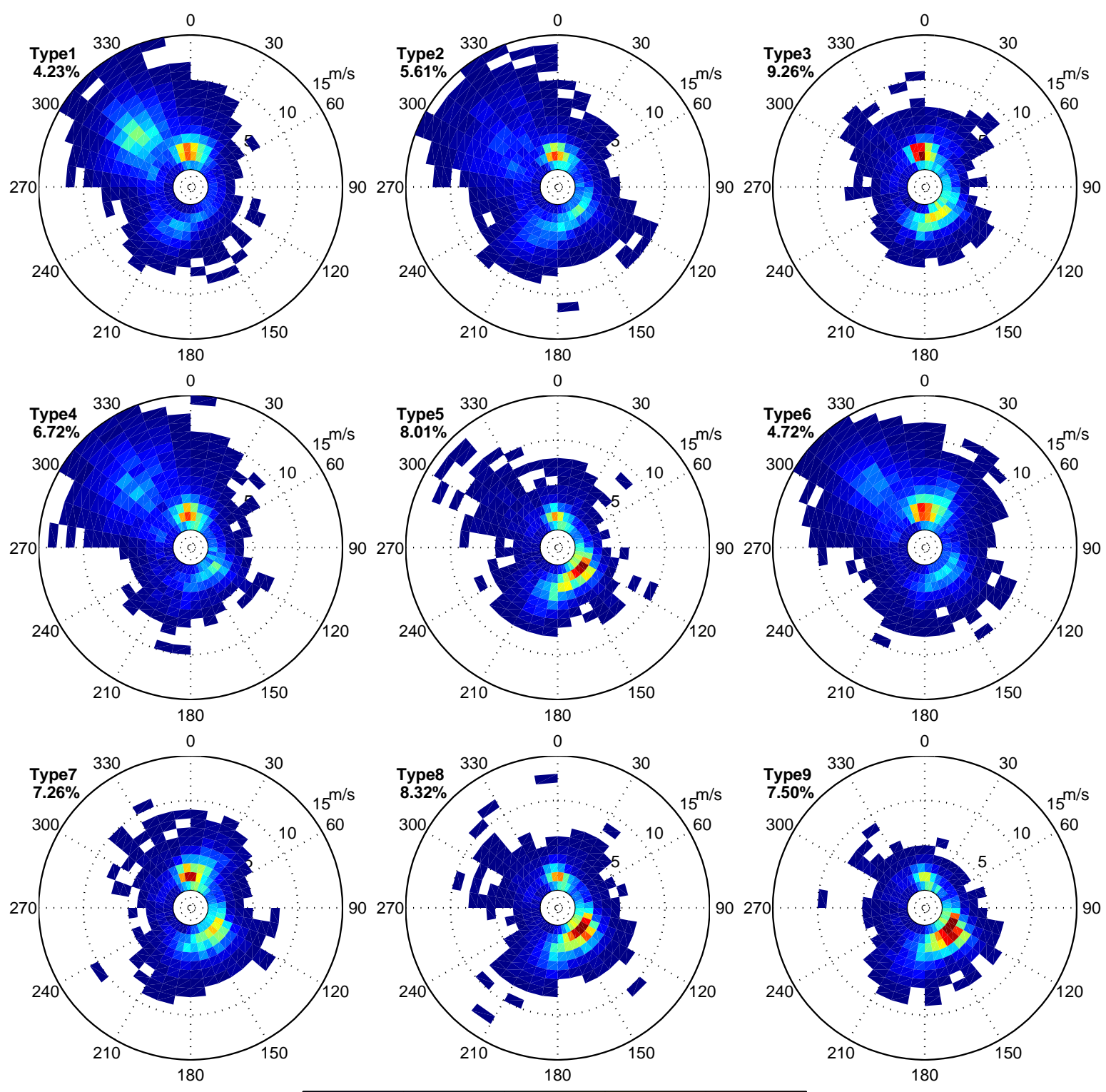

Fig. 4. Wind frequency (\%) of the nine circulation types at BCIA. The top-left numbers represent calm wind frequencies.

types, while types 7 and 5 had the lowest daily maximum PBL height.

Most circulation types showed relatively high frequencies of northerly and southeasterly winds with speeds of 2$3 \mathrm{~ms}^{-1}$ (Fig. 4). As shown in Fig. 1, Beijing is located to the southeast of a mountain range with an average height of more than $1500 \mathrm{~m}$. The diurnal cycle of mountain-valley breezes plays an important role in the local circulation near Beijing. To reveal the source of air masses over Beijing on multiple scales in detail, FLEXPART-WRF model was used to obtain the footprint maps of trajectories for the circulation types during the period June 2008 to May 2009 (Fig. 5). Each circulation type, backed by plume trajectory analyses, dictated the long-range transport and distinctive air mass affecting dispersion conditions. This determined the synopticscale and mesoscale meteorological behaviors controlling the transport of regional air pollutants. The mean footprints in the local region $\left(39.4^{\circ}-40.4^{\circ} \mathrm{N}, 155.8^{\circ}-116.8^{\circ} \mathrm{E}\right)$ were also calculated (upper left digits in Fig. 5). The main analytical results were as follows:

1. CT 1 was characterized by a northwesterly origin, with the fewest local and southeasterly air mass sources among all the types. CT 6 showed the second fewest local and southwesterly air mass sources, with northerly to easterly trajectories. 

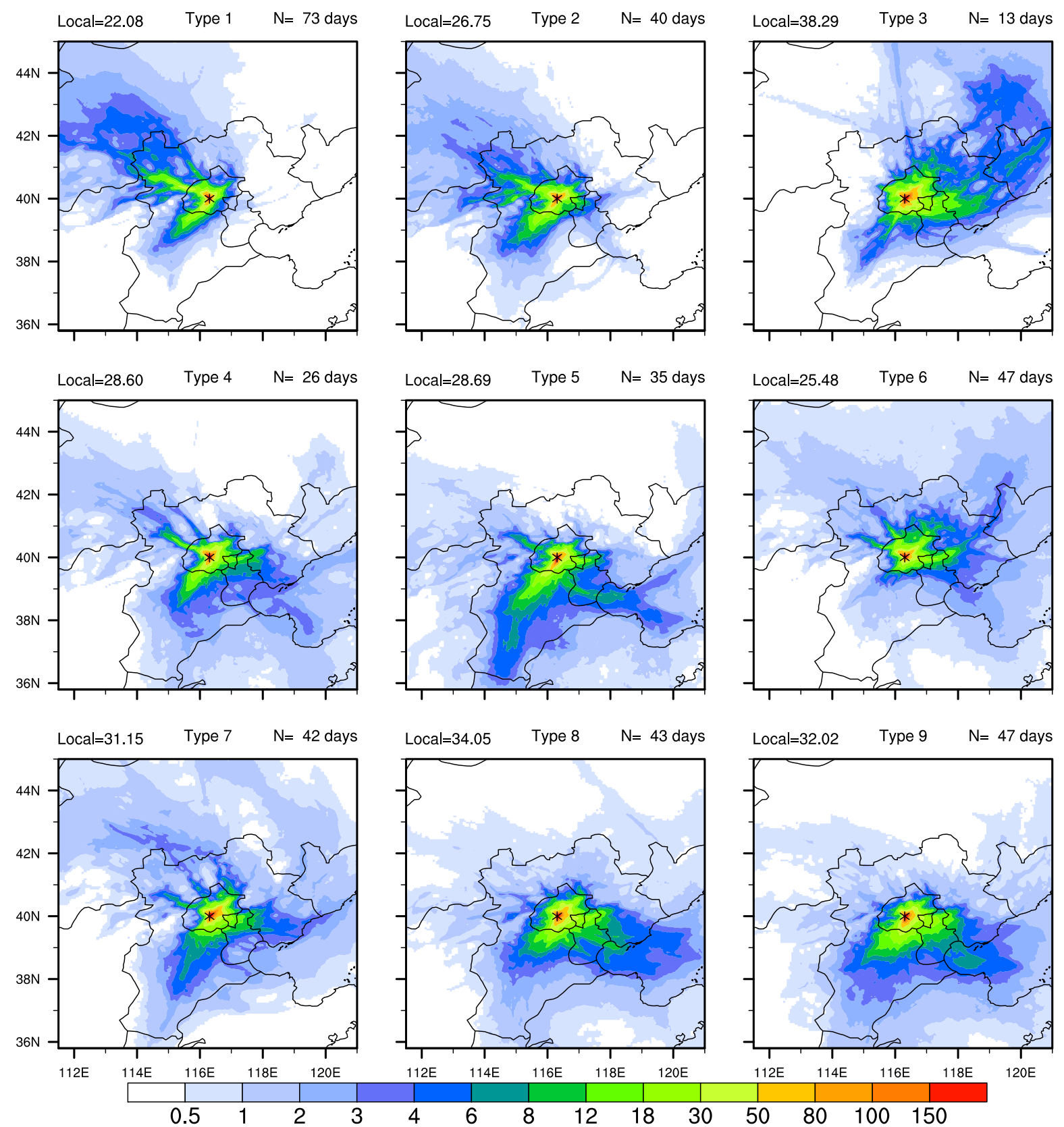

Fig. 5. Averaged footprints (residence times of 48-h backward trajectories) for each circulation type during the period June 2008 to May 2009. The markers denote the location of the PKU site.

2. CTs 5, 8, and 9 were associated with southerly and southeasterly trajectories. Type 5 had the most southern sources among all circulation types. The southern source regions (e.g. Hebei province, Tianjin and Shandong province) have large emissions of anthropogenic air pollutants (shown in Q. Zhang et al., 2009). The local area was more influenced by pollutants emitted from the south (e.g. Shijiazhuang, Handan) and southeast (Tianjin) of Beijing under these conditions.
3. CT 3 had the most local sources and frequent northeasterly origins.

\section{Relationships between circulation type and air quality}

Because of the significant differences in meteorological conditions and footprints of 48-h backward trajectories among the circulation types described in Sect. 3, we evaluated the relationship between circulation type and air quality in Beijing. 
Table 1. Means of local (BCIA) meteorological variables classified by circulation types during the 2000-2009 period. The daily maximum PBL height was calculated from the WRF model for 1 yr (June 2008 - May 2009).

\begin{tabular}{lrrrrrrrrrr}
\hline $\begin{array}{l}\text { Circulation } \\
\text { type }\end{array}$ & $\begin{array}{r}\text { Frequency } \\
(\%)\end{array}$ & Description & $\begin{array}{r}\text { Temp. } \\
\left({ }^{\circ} \mathrm{C}\right)\end{array}$ & $\begin{array}{r}\text { RH } \\
(\%)\end{array}$ & $\begin{array}{r}\text { Pressure } \\
(\mathrm{hPa})\end{array}$ & $\begin{array}{r}\text { Wind } \\
\text { speed } \\
\left(\mathrm{m} \mathrm{s}^{-1}\right)\end{array}$ & $\begin{array}{r}\text { Cloud } \\
\text { cover } \\
(\mathrm{okta})\end{array}$ & $\begin{array}{r}\text { Visibility } \\
(\mathrm{km})\end{array}$ & $\begin{array}{r}\text { Precip. } \\
\text { Day Freq. } \\
(\%)\end{array}$ & $\begin{array}{r}\text { PBL } \\
\text { Height } \\
(\mathrm{km})\end{array}$ \\
\hline 1 & 17.6 & $\mathrm{WH}+$ & 4.73 & 37.2 & 1022.4 & 3.72 & 0.93 & 18.5 & 1.6 & 1.34 \\
2 & 11.8 & $\mathrm{WSH}$ & 17.73 & 50.7 & 1006.9 & 2.95 & 2.06 & 12.4 & 9.1 & 1.76 \\
3 & 6.1 & $\mathrm{NEH}$ & 12.28 & 65.7 & 1017.7 & 2.08 & 3.19 & 11.1 & 17.0 & 1.14 \\
4 & 9.6 & $\mathrm{~L}$ & 11.94 & 60.0 & 1012.1 & 3.20 & 4.14 & 9.4 & 21.8 & 1.34 \\
5 & 8.3 & $\mathrm{U}$ & 17.55 & 69.0 & 1008.8 & 2.12 & 3.48 & 6.0 & 14.9 & 1.17 \\
6 & 15.6 & $\mathrm{NWH}$ & 14.54 & 59.3 & 1012.2 & 3.28 & 3.36 & 14.3 & 20.5 & 1.38 \\
7 & 11.0 & $\mathrm{NH}$ & 6.58 & 58.0 & 1020.4 & 2.25 & 3.59 & 9.8 & 14.9 & 1.06 \\
8 & 11.5 & $\mathrm{EH}$ & 19.2 & 72.4 & 1008.8 & 2.10 & 3.79 & 6.6 & 19.8 & 1.29 \\
9 & 8.6 & $\mathrm{NWL}$ & 15.03 & 66.9 & 1012.0 & 2.19 & 4.01 & 6.7 & 17.3 & 1.28 \\
\hline Total Mean & & & 12.75 & 57.6 & 1013.9 & 2.7 & 2.98 & 11.4 & 14.3 & 1.32 \\
\hline
\end{tabular}

Table 2. Relationship between weather types and high pollution episodes in Beijing. The standardized ratios of the percentage of days in the upper $20 \%$ for $\mathrm{PM}_{10}, \mathrm{O}_{3}, \mathrm{SO}_{2}, \mathrm{NO}_{2}, \mathrm{NO}_{\mathrm{x}}, \mathrm{CO}, \mathrm{BC}$, AERONET AOD, and extinction coefficients (calculated from the visibility) to the overall percentage of occurrence of the particular circulation type are shown.

\begin{tabular}{lrccccccccc}
\hline $\begin{array}{l}\text { Circulation } \\
\text { type }\end{array}$ & $\begin{array}{r}\text { Frequency } \\
\%\end{array}$ & $\mathrm{PM}_{10}$ & $\mathrm{O}_{3}$ & $\mathrm{SO}_{2}$ & $\mathrm{NO}_{2}$ & $\mathrm{NO}_{\mathrm{x}}$ & $\mathrm{CO}$ & $\mathrm{BC}$ & $\begin{array}{r}\text { AERONET } \\
\text { AOD }\end{array}$ & $\sigma_{\text {ext }}$ \\
\hline 1 & 17.6 & 0.38 & 0.32 & 1.47 & 0.75 & 1.15 & 0.87 & 0.48 & 0.12 & 0.16 \\
2 & 11.8 & 1.03 & 1.45 & 0.34 & 0.92 & 0.86 & 0.53 & 0.97 & 0.56 & 0.73 \\
3 & 6.1 & 1.22 & 0.63 & 1.17 & 1.04 & 0.71 & 0.94 & 1.34 & 0.71 & 1.05 \\
4 & 9.6 & 1.04 & 0.68 & 1.49 & 0.83 & 1.42 & 1.36 & 1.06 & 1.18 & 1.09 \\
5 & 8.3 & 1.65 & 1.49 & 1.04 & 2.01 & 1.57 & 1.72 & 1.65 & 2.52 & 2.10 \\
6 & 15.6 & 0.64 & 1.01 & 0.42 & 0.29 & 0.55 & 0.42 & 0.60 & 0.59 & 0.52 \\
7 & 11.0 & 1.16 & 0.29 & 2.13 & 1.16 & 1.30 & 1.74 & 1.31 & 1.11 & 1.12 \\
8 & 11.5 & 1.49 & 1.58 & 0.49 & 1.14 & 0.65 & 0.71 & 1.40 & 2.17 & 1.73 \\
9 & 8.6 & 1.29 & 1.71 & 0.93 & 1.58 & 1.25 & 1.45 & 1.13 & 2.28 & 1.68 \\
\hline
\end{tabular}

The air quality data investigated in this section were described in Sect. 2 in detail.

\subsection{Circulation type in relation to optical air quality}

Atmospheric visibility measurements can serve as a surrogate for optical air quality and for smaller size $(<2.5 \mu \mathrm{m})$ particulate fractions (Bäumer et al., 2008; Sloane, 1983, 1984). Low visibility is strongly correlated with heavy pollution and adverse health effects in megacities (Molina and Molina, 2004; Atkinson et al., 2010; Li et al., 2011; Quan et al., 2011). We examined the horizontal visibility at BCIA under each circulation type during the period from 2000 to 2009. Figure 6 shows the large variation in the visibility distribution among the circulation types. CTs 1 and 6 are associated with good visibility. The average visibilities (with $\pm 1 \sigma$ ) for these two types were $18.5 \pm 8.3 \mathrm{~km}$ and $14.3 \pm 8.5 \mathrm{~km}$, respectively. These averages were both significantly different from the mean for any other circulation types (Table S2). The CT 1 was dominated by air masses from relatively clean regions northwest of Beijing and exhibited the lowest tempera- ture and humidity among all circulation types. The type 6 circulation was more frequent in summer, with a relatively high average humidity $(59.3 \%)$. Because hygroscopic growth of aerosol particles can be intensified by higher RH values (Liu et al., 2011), increased aerosol mass extinction efficiency and reduced visibility are often observed in more humid conditions (Q. H. Zhang et al., 2010). However, under the CT 6, the higher average wind speed and more frequent precipitation rate (Table 1) helped to reduce the concentration of aerosols through mixing and wet scavenging processes in the atmosphere. Previous study (e.g. Q. H. Zhang et al., 2010) also shows good visibility in Beijing is associated with northerly, northwesterly, and westerly wind greater than $3 \mathrm{~ms}^{-1}$, while the low visibility is associated with weak wind and wind from the south, the southeast, and the east. The mean visibility for CT 5 was $6.0 \pm 3.5 \mathrm{~km}$ that was significantly lower than any other CT (at a 0.05 level). And poor average visibility (the lower $20 \%$ ) was also found most frequently in type 5 (Table 2), in which the winds were mostly weak and associated with southwesterly transport pathways. CTs 8 and 


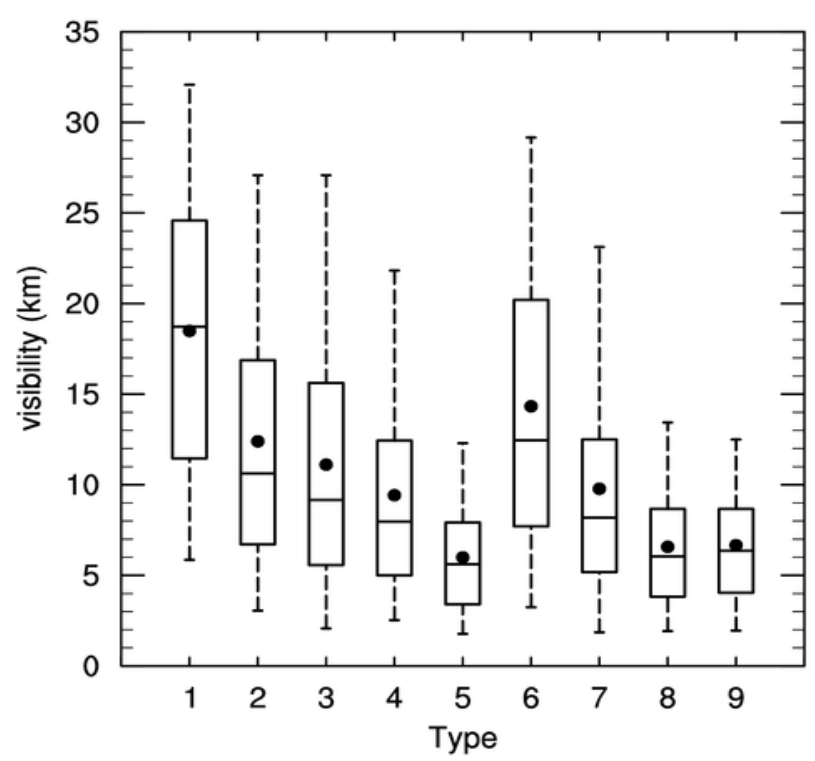

Fig. 6. Daily mean visibility at Beijing airport within the nine clusters. The solid dot denotes the mean. The horizontal lines across the box are the averages of the median, first, and third quartiles, respectively, while the lower and upper crosses represent the means of the 5th and 95th percentiles, respectively.

9 displayed the highest $\mathrm{RH}$ values $(72.4 \%$ and $66.9 \%)$ and pollutant sources from the southwest and southeast of Beijing (Figs. 4 and 5), resulting in the highest impairment of visibility among the CTs. We also found that haze and fog mainly occurred under CTs 5, 8, and 9 (Table 2).

Although the pathways of CTs 1 and 2 were similar, the relatively high $\mathrm{RH}$ value under type 2 conditions resulted in lower visibility as compared with type 1 . While types 4 and 5 had similar pathways, type 4 had better visibility due to the higher wind speed, precipitation rate, PBL height, and lower RH.

Clear-sky AOD data from the AERONET Beijing and Xianghe (XH) sites during the period March 2001 to December 2009 were also used to investigate the dependence of daytime air quality on the circulation type. The averaged and minimum valid days at Beijing site in the CTs were 205 and 105 days, respectively; the numbers were 136 and 63 days, respectively, at Xianghe site. For the Beijing site, the results showed that types 5,9 , and 8 were associated with the highest AOD and types 1 and 6 were associated with the lowest AOD (Fig. 7). The mean AOD of type 1 was $0.28 \pm 0.27$, while the mean AOD of type 9 was $1.21 \pm 0.59$. The result at the XH rural site was similar to that at the Beijing site. The highest AOD $(1.15 \pm 0.57)$ at $\mathrm{XH}$ was found in CT 5. These results also confirmed the significant difference in light extinction among the circulation types.

The AOD data (Collection 5) from MODIS Level-2 products with $10-\mathrm{km}$ nadir spatial resolution were used to reveal the spatial distribution of clear-sky aerosols under each cir- culation type (Fig. 8). The North China Plain had relatively low mean AOD (averaged value 0.28 over Beijing) during the occurrence of CT 1 due to the long-range transport pathway of dry and mostly clean air masses from northwestern regions. In contrast, CTs 5, 8, and 9 were associated with high AOD values ( $>1.0)$ over the Beijing urban region, especially over the southeastern and southern parts of Beijing. In these cases, low-level air pollutants from southern and southeastern sources are thought to have been advected to urban Beijing by southerly winds and blocked by the mountains, causing worse pollution in urban areas (Q. H. Zhang et al., 2010). Air craft study of vertical aerosol and AOD suggested that the surface level aerosol concentration was a key factor which greatly alters the value of AOD over Beijing and its surroundings (Liu et al., 2009). Another reason was that CTs 5,8 , and 9 were all associated with relatively high RH ( $69 \%$, $72.4 \%$, and $66.9 \%$ ), which is favorable to the growth of hygroscopic aerosols and increase of light extinction. In CT 6, the mean AOD over Beijing was 0.53, indicating that type 6 was advantageous for the dispersion and removal of pollutants, with weaker advection of pollutants from southern and southeastern sources (Fig. 5). The AOD values over Beijing (BJ), Shijiazhuang (SJZ), Tianjin (TJ), Handan (HD), and Tangshan (TS) (shown in Fig. 1) were high during type 4. The distribution of AOD in type 4 was the most localized of all the types, suggesting the dominance of local emission. This result also suggests that synoptic situations characterized by weak advection contribute to stagnant air and the accumulation of pollutants over emission sources.

Three different datasets of atmospheric extinction (i.e. visibility, AERONET and MODIS AODs) were used in this study to investigate the relationships between synoptic circulation and optical air quality. While all three of them have their own unique strengths and weaknesses, they complemented each other to provide more holistic information about atmospheric extinction, and concluded the similar correlations between CTs and air quality. The significant differences of cloud-free AODs among the CTs may indicate that aerosol radiative forcing on atmosphere strongly relies on synopticscale circulation pattern.

\subsection{Dependence of aerosol loading on circulation type}

Exposure to particulate air pollution is associated with respiratory, cardiovascular and other morbidity and enven increased mortality (Dockery and Pope, 1994; Downs et al., 2007; Magari et al., 2001; Pope Iii and Dockery, 2006). $\mathrm{PM}_{10}$, the leading pollutant in Beijing, was examined in relation to circulation types. Box-and-whisker plots (Fig. 9a) show the 5th and 95th percentiles, the first and third quartiles, and the median and mean values of $\mathrm{PM}_{10}$ concentration by circulation type. CT 1 was found to be associated with a low concentration of particulate pollutants $\left(90.3 \pm 76.3 \mu \mathrm{g} \mathrm{m}^{-3}\right)$. The concentration was significantly different from the mean for any other circulation types 

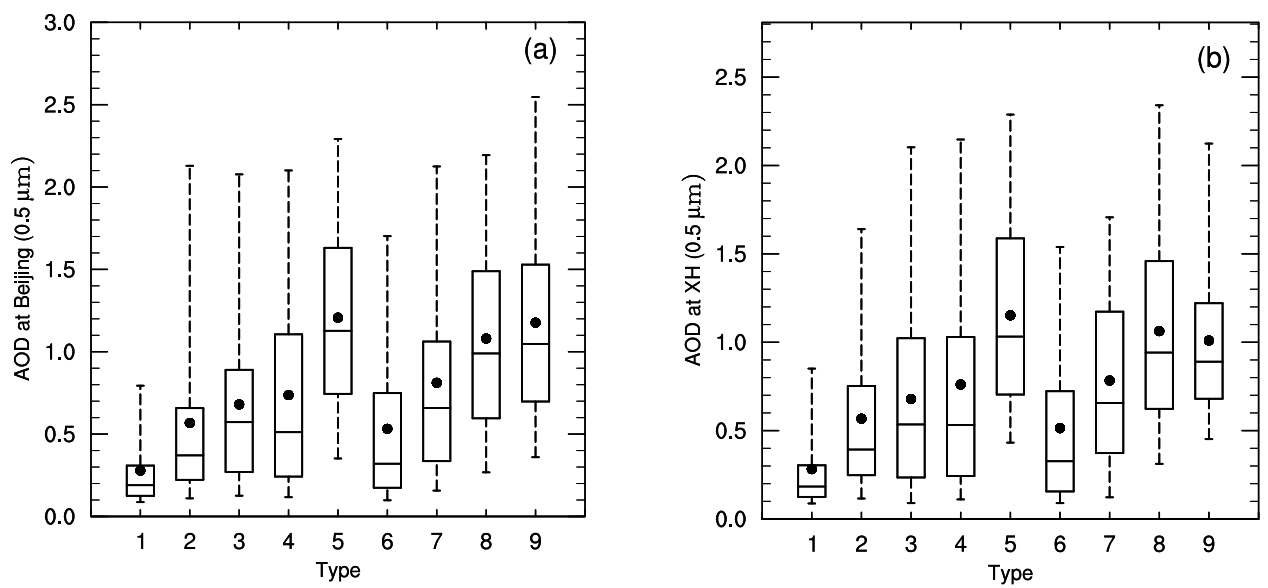

Fig. 7. AOD at AERONET stations in Beijing (a) and Xianghe (b) within the nine clusters. Solid dots denote the mean. The horizontal lines across the box are the median, first, and third quartiles, respectively, while the lower and upper crosses represent the 5th and 95th percentiles, respectively.

(Table S3). This was mainly due to the frequent clean sources and good ventilation conditions that are characterized by high wind speeds and long transport pathways. The mean concentration of $\mathrm{PM}_{10}$ for CT 6 was $111.7 \pm 89.6 \mu \mathrm{g} \mathrm{m}^{-3}$. In contrast, types 5,8 , and 9 were characterized by frequent stagnant conditions and thus elevated $\mathrm{PM}_{10}$ concentrations $\left(173.4 \pm 105.8 \mu \mathrm{g} \mathrm{m}^{-3}, 158.4 \pm 90.0 \mu \mathrm{g} \mathrm{m}^{-3}\right.$, and $151.2 \pm 93.1 \mu \mathrm{g} \mathrm{m}^{-3}$, respectively). Dust storms were one of the major non-Beijing $\mathrm{PM}_{10}$ sources in spring, but their frequency occurrence decreased significantly in recent years (Zhu et al., 2008). With respect to long-term (annual) mean, the external $\mathrm{PM}_{10}$ sources were mainly from the south and east-south places (e.g. Hebei province, Tianjin and Shandong). The maximum non-Beijing contribution was estimated to be $60-80 \%$ when Beijing encountered heavy $\mathrm{PM}_{10}$ pollution episode with sustained wind flow from the south (An et al., 2007; Chen et al., 2007). Although dust storm had partly contributed to the surface $\mathrm{PM}_{10}$ loadings during fast northerly transport paths, the averaged $\mathrm{PM}_{10}$ concentrations in the CTs with northern air masses (e.g. CT 1) were significantly lower than those in CTs 5, 8 and 9 with southerly transport paths.

Black carbon (BC) is an important component of the atmosphere contributing to global warming (Wang, 2004; Ramanathan and Carmichael, 2008) as well as an important species of particulate pollutant in densely populated regions (Highwood and Kinnersley, 2006). As the by-product of fossil fuel combustion, BC is widely used as indicator of traffic pollution, and its detrimental influence on human health has been well documented (e.g. W. Lin et al., 2011; Patel et al., 2010; Jansen et al., 2005). Here, we discuss the dependence of urban $\mathrm{BC}$ concentration on each circulation type (Fig. 9b). Our results show the lowest BC mass concentration $\left(4.1 \pm 3.8 \mu \mathrm{g} \mathrm{m}^{-3}\right)$ in CT 1 , with a median of only $2.9 \mu \mathrm{g} \mathrm{m}^{-3}$. Type 6 also had low BC readings compared to the mean concentration. This indicated that these two types had good dispersion conditions (e.g. high wind speeds and large PBL height) and more frequent air mass trajectories from clean sources (Table 1 and Fig. 5). The statistical test confirmed the significant difference of the mean BC concentration associated with CT 1 and 6 from that for any other CTs (Table S3). Conversely, types 5 and 8 were characterized by high BC concentrations $\left(8.4 \pm 4.9 \mu \mathrm{g} \mathrm{m}^{-3}\right.$ and $7.6 \pm 4.3 \mu \mathrm{g} \mathrm{m}^{-3}$, respectively). The first quartiles of these two types were about $10 \mu \mathrm{g} \mathrm{m}^{-3}$. Type 3 also had high BC loading for its limited dispersion weather conditions, possibly due to its poor ventilation conditions (Fig. 5). On the whole, the urban $\mathrm{BC}$ in Beijing was characterized by high concentration (5-yr average of $6.7 \mu \mathrm{g} \mathrm{m}^{-3}$ ) and strong dependence on the CT. In general, the $\mathrm{PM}_{10}$ and $\mathrm{BC}$ concentration in Beijing were consistent for each circulation type.

\subsection{Relationship of gaseous pollutants and circulation types}

In recent years, the increasing trend of gaseous pollution in urban regions (e.g. ozone and nitrogen oxides) (Tang et al., 2009; Wang et al., 2012) has posed new challenges to air quality management in Beijing. Understanding the relationship between the synoptic weather situation and gaseous pollution is important for air quality forecast and management. Figure 10 shows the 5th and 95th percentiles, the first and third quartiles, and the median and mean values of $\mathrm{SO}_{2}, \mathrm{NO}_{2}$, $\mathrm{NO}_{\mathrm{x}}, \mathrm{CO}$, and daily maximum $\mathrm{O}_{3}$ for different circulation types. Concerning the daily maximum ozone mixing ratio, CTs 8,9 , and 5 were associated with high ozone concentrations, mainly because of the high temperature, $\mathrm{RH}$, and sunshine values and frequent stagnant air in warm seasons (Table 1 and Fig. 3). The ozone concentration in type 1 was lower than other types because of the low temperature, high 

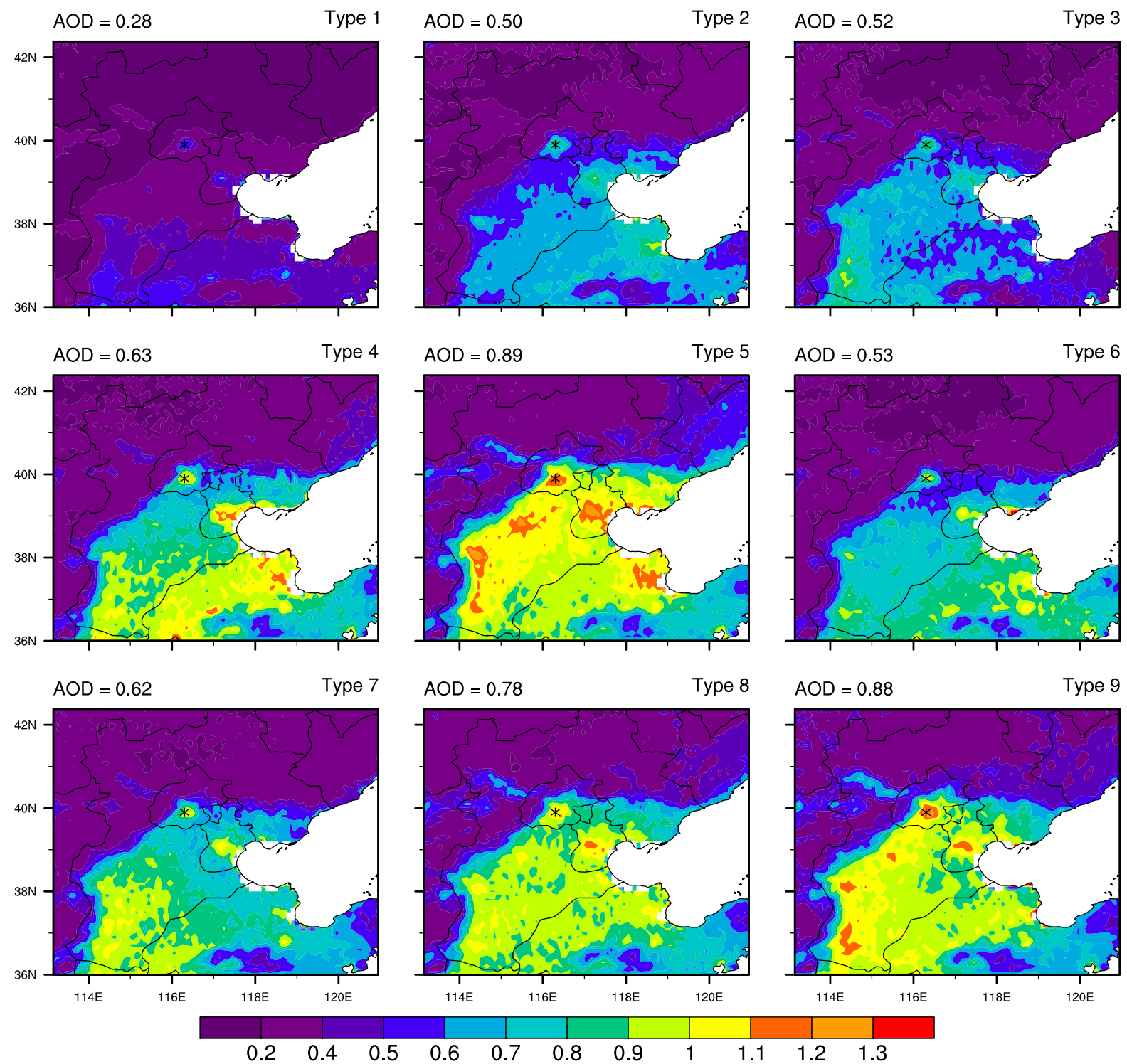

Type 9
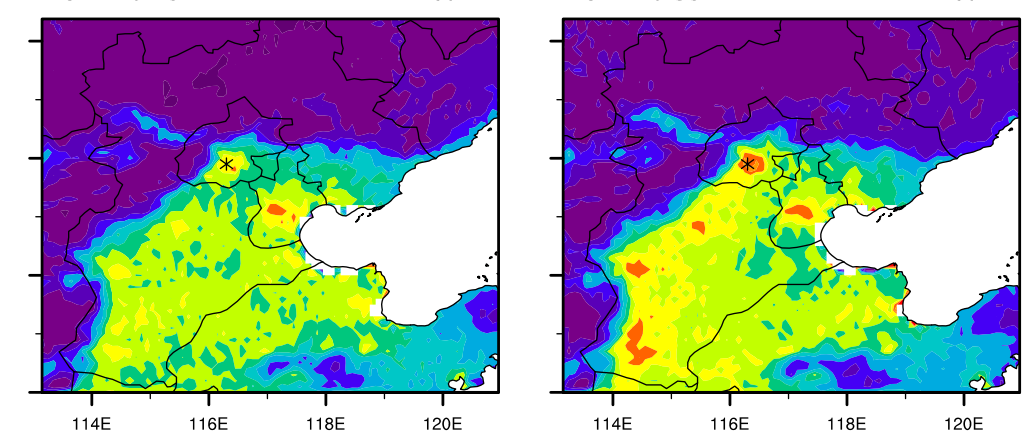

$0.2 \quad 0.4 \quad 0.5$

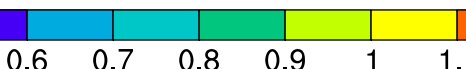

$1.2 \quad 1.3$

Fig. 8. Averaged 10-km AOD (MODIS $550 \mathrm{~nm}$ ) maps for each circulation type from February 2000 to December 2009 (the upper left number denotes the area mean over Beijing).

wind speed, and less polluted sources. The lowest concentrations of $\mathrm{CO}, \mathrm{NO}_{2}, \mathrm{NO}_{\mathrm{x}}$, and $\mathrm{SO}_{2}$ were related to type 6 , and the average concentrations associated with type 6 were mostly different from the mean for other types at a 0.05 significance level (Table S4). In contrast, CT 5 was characterized with highest mixing ratio of $\mathrm{CO}, \mathrm{NO}_{2}$ and $\mathrm{NO}_{\mathrm{x}}$. The large distributions (variances) of the gaseous concentration in some specific CT were partly due to the limitation of the measurement data duration and the large variations of the emission rate. Concentrations of $\mathrm{SO}_{2}$ in types 7 and 1 were the highest among all the types, unlike the results for the other pollutant species. This was mainly because $\mathrm{SO}_{2}$ in Beijing types 1 and 7 occurred most frequently in winter when fossil fuel combustion for heating is intensive in North China.
The frequent high concentration of $\mathrm{SO}_{2}$ in winter (shown in Supplement Fig. S7) could significantly elevate the averaged $\mathrm{SO}_{2}$ mixing ratio in CTs 1 and 7. This result indicates that the potential impact of synoptic weather systems on gaseous pollutants and particulate matters can vary. Particulate pollutants depend more on transport and dispersion conditions, while gaseous pollutants are more sensitive to meteorological variables (e.g. temperature, $\mathrm{RH}$, cloud fraction) and emission sources. 

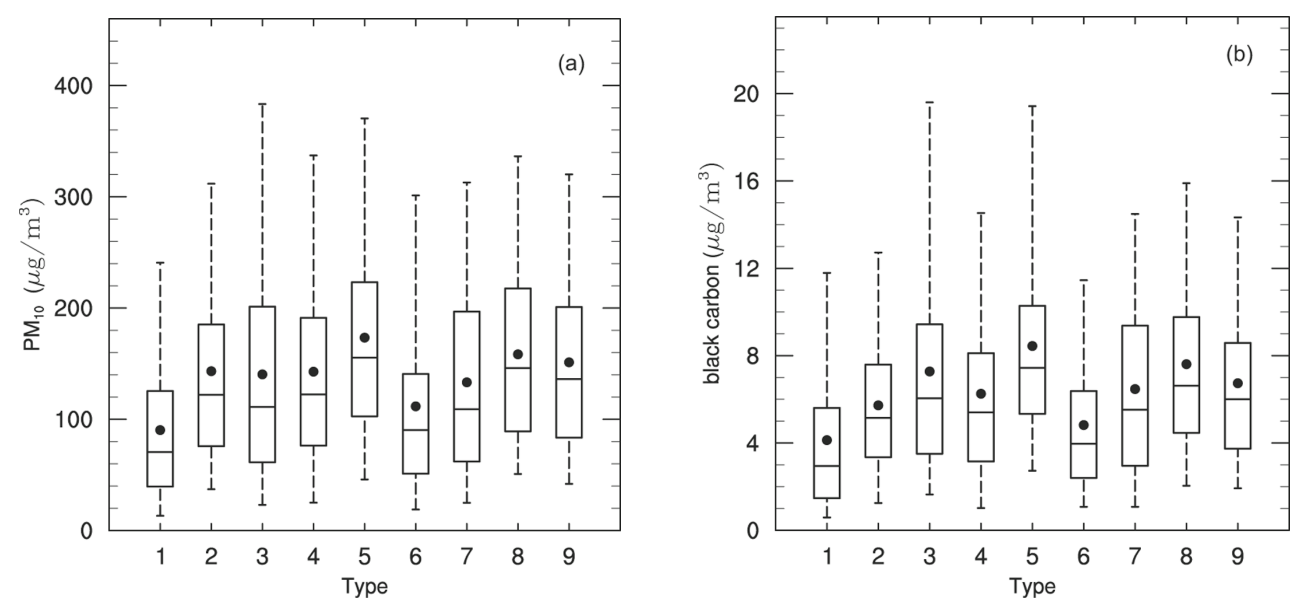

Fig. 9. $\mathrm{PM}_{10}$ (a) and $\mathrm{BC}$ (b) concentrations at the PKU station vs. circulation type during the period 2005 to 2009 . Solid dots denote the mean. The horizontal lines across the box show the median and first and third quartiles, while the lower and upper crosses represent the 5 th and 95th percentiles, respectively.

\section{Air quality and synoptic circulation during the Olympics}

The Chinese government started implementing pollutant emission control measures in Beijing and the surrounding area from 20 July 2008. Figure 11 shows hourly variations in visibility, $\mathrm{PM}_{10}$, sulfates, $\mathrm{BC}, \mathrm{SO}_{2}$, surface temperature, precipitation, and 24-h backward trajectory direction and origin height from 21 July to 1 September 2008. Gray shadings indicate the three pollution episodes (with high aerosol loadings and low visibility) before and after the Olympics (23-28 July, 4-8 August, 26-29 August), and pink shading indicates the period of the Olympics. The results show that under emission control the air quality improved significantly during the Olympics. The temperature curve indicates the relative cooling during the Olympics compared to those three pollution episodes. The 24-h backward plume trajectory analyses showed that clean episodes were associated mainly with air masses of northwestern and northeastern origins from high levels above the ground (shown as vectors in Fig. 11), while during the pollution episodes, air masses were dominated by southwestern and southeastern origins near the surface. These 24-h backward trajectories are present instead because that a part of $48 \mathrm{~h}$ back-trajectories were out of domain, especially for northerly transport paths. It would lead to some error or missing data if the main positions of the $48 \mathrm{~h}$ backward trajectories were calculated. The concurrent measurements of sulfur dioxide and sulfate at the PKU site revealed the total sulfur variation in the atmosphere. The polluted episodes were all characterized by high concentrations of both sulfate and total sulfur, particularly in the later period. The circulation types (shown in the bottom of Fig. 11) also revealed that pollution episodes were associated with the persistent control of circulation types 5,8 , and 9 , and clean episodes were associated with types 1,6 , and 2 . The relation- ships between air quality, meteorological conditions, and circulation types were consistent with the relatively long-term analyses described in Sects. 3 and 4. In summary, analysis of the time series of circulation patterns and air quality parameters $\left(\mathrm{PM}_{10}, \mathrm{BC}\right.$, sulfate, $\mathrm{SO}_{2}$, and visibility) during the emission control period indicated that CTs were the primary drivers of day-to-day variations in air pollutants over Beijing and its vicinity.

Interestingly, at the beginning (first 20 days) of emission control, there were two episodes of heavy pollution in which $\mathrm{PM}_{10}$ mass concentrations often exceeded $200 \mu \mathrm{g} \mathrm{m}^{-3}$, BC concentration was frequently elevated to above $7 \mathrm{\mu g} \mathrm{m}^{-3}$, and visibility was always below $6 \mathrm{~km}$ in Beijing. However, the aerosol loadings sharply decreased and "blue sky" (i.e. visibility $>19 \mathrm{~km}$; Q. H. Zhang et al., 2010) conditions frequently appeared in Beijing after the opening ceremony of the Olympics (Fig. 11). In turn, another pollution episode (26-29 August) followed the Olympics. Why did air quality improve significantly during the Olympic period when emission control had started earlier from the end of July? Apparently, the large variations in air pollutant concentrations and the delay in air quality improvement cannot be explained only by the control measures. However, it could be a justified explanation that the pollutant episodes and clean Olympics episode were characterized by different circulation types. The frequent occurrence of CT 6 during the Olympics and CTs 5, 8 and 9 in the polluted episodes may have been an important reason for the difference. The frequency anomaly of CTs is mainly affected by large circulation changes. As mentioned in Section 3, the western Pacific subtropical high is one of the most important atmospheric influences on weather and climate in (east) China in summer. The impact of the subtropical high on the air quality over Beijing and its surroundings has been addressed by X. Zhang et al. (2009) and Sun et al. (2010). We compared 500-hPa geopotential height maps 

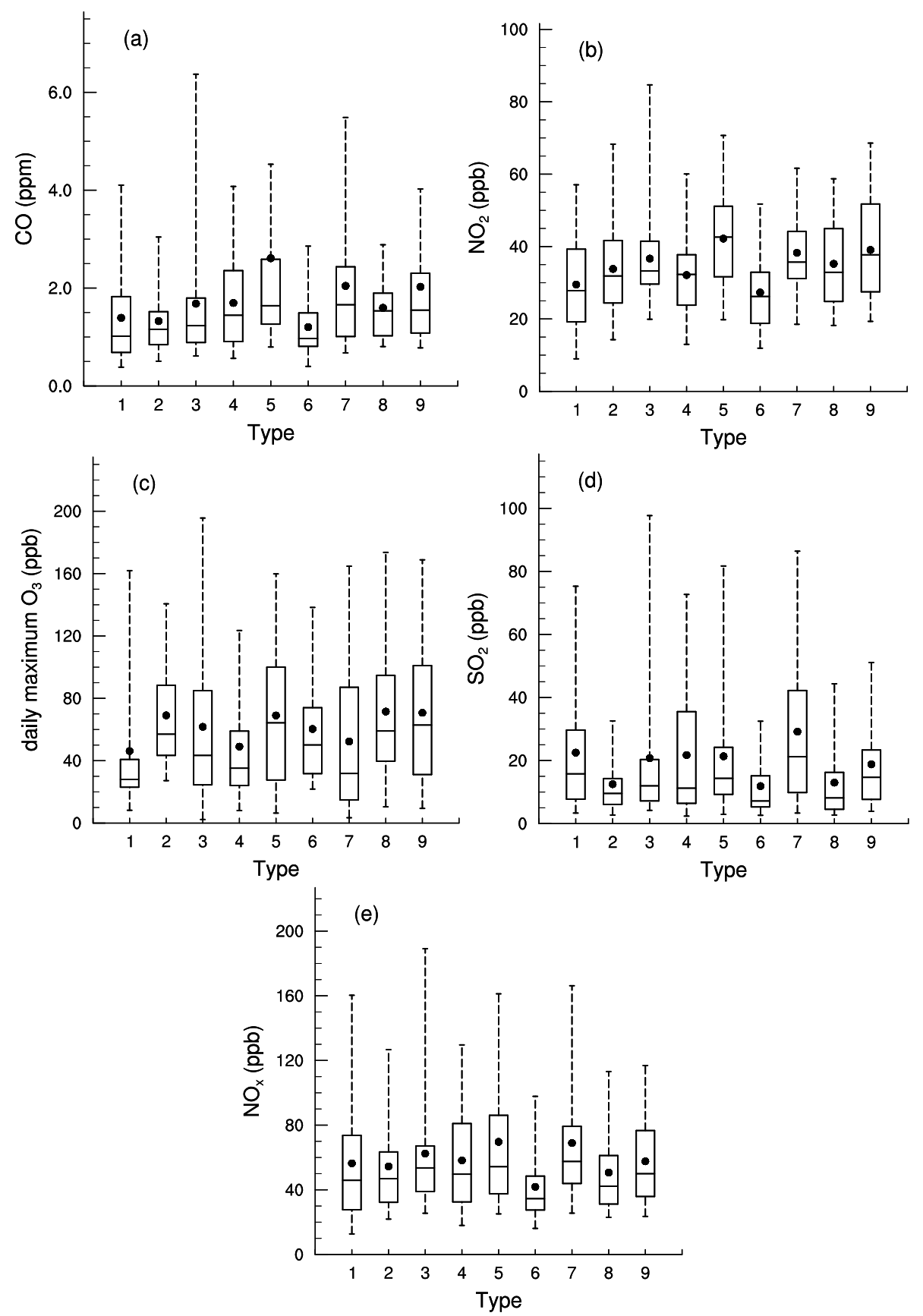

Fig. 10. As in Fig. 6 but for $\mathrm{CO}, \mathrm{NO}_{2}$, daily maximum $\mathrm{O}_{3}, \mathrm{SO}_{2}$ and $\mathrm{NO}_{\mathrm{x}}$ mixing ratio at $\mathrm{PKU}$ during the period August 2006 to October 2008.

during the Olympics with those during the two pollution episodes and the 10 years mean (Supplement Fig. S8). The subtropical high (the contour of $5880 \mathrm{gpm}$ ) dominated over Korea and Japan before the Olympics but shifted to the southeast during the Olympics. When the subtropical high was located over Korea and Japan, Beijing experienced high temperatures and southern air mass origins (Fig. 11), which were associated with bad air quality. When the subtropical high moved far to the southeast, the upper-level weather charts (not shown) show that Beijing and its surrounding area would have been dominated by eastward-moving mid-latitude baroclinic waves, which cause northerly winds at the surface. During the Olympic Games, the subtropical high moved to the southeast, and Beijing was mainly affected by frequent eastward-moving troughs and cold continental highs. This resulted in a high frequency of CT 6 , which was favorable for clean air quality. 


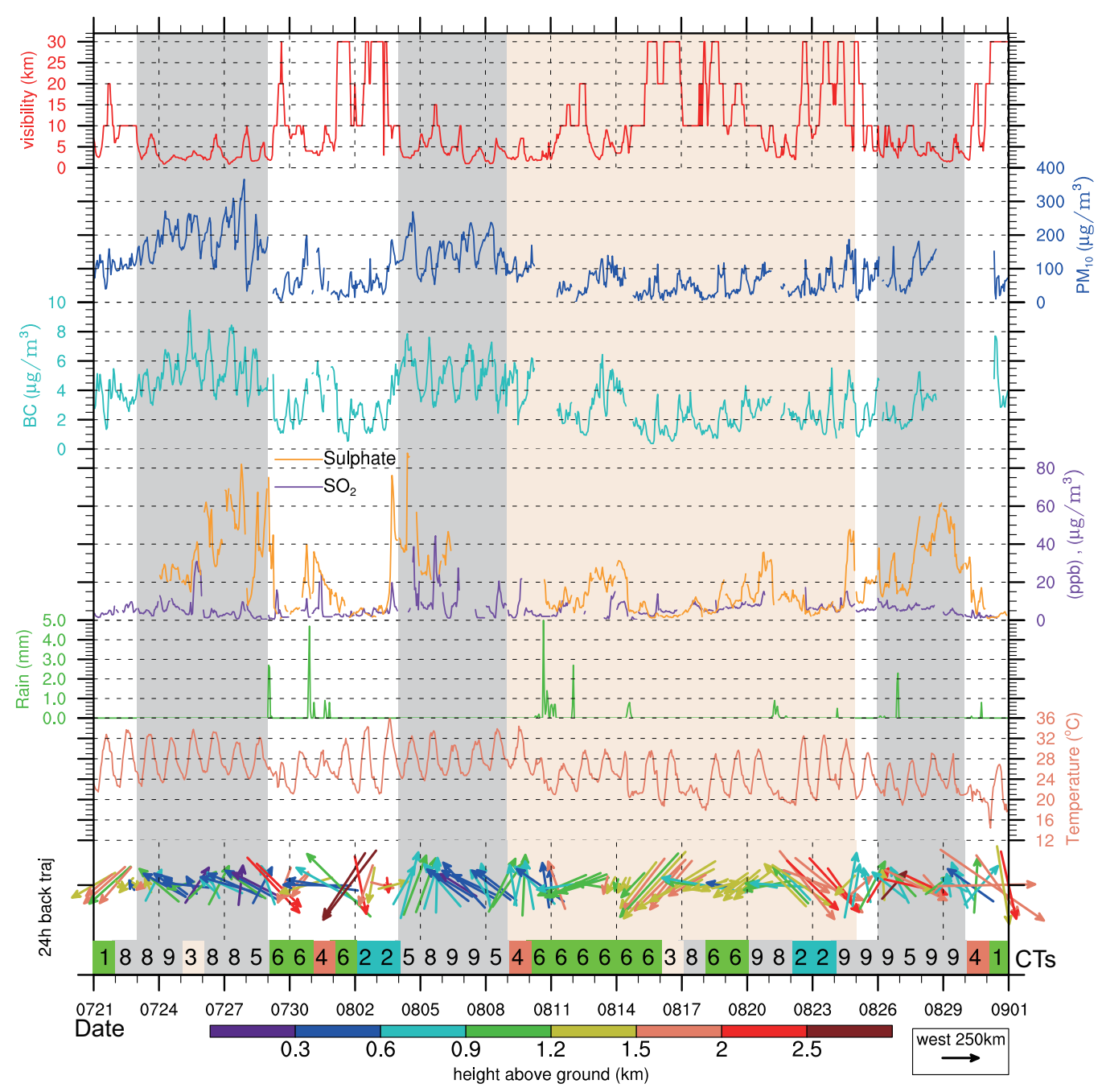

Fig. 11. Time series of (top to bottom) hourly visibility, $\mathrm{PM}_{10}, \mathrm{BC}$, sulfate and $\mathrm{SO}_{2}$, surface temperature, precipitation, and the 24-h backward plume position at 6-h intervals (direction and distance shown as arrows, height above ground shown in colors) and daily circulation types (CTs) from 21 July to 31 August 2008. Pink shading indicates the period of the Olympic Games, while gray shading represents the pollution episodes in Beijing.

A comparison of circulation type frequencies during the Beijing Summer Olympics to the mean frequency in August from 2000 to 2009 is shown in Fig. 12. Compared with the 10 -yr mean frequency of occurrence, the significant difference was that CT 6 occurrence was doubled and CT 5 (the most polluted type) disappeared during the Olympic Games. This situation was also indicated by the average location of the subtropical high during the Olympics in 2008 and in August from 2000 to 2009 (Fig. S8). Furthermore, the footprints of 48-h backward plume trajectories were calculated for three periods: the Olympics, two pollution episodes (23-28 July and 4-8 August), and the whole summer (June, July, August) of 2008 (shown in Fig. 13). The northeasterly air mass was dominant during the Olympics in 2008. However, southern origins prevailed in the two pollution periods. Compared with the mean footprint for the whole summer, the footprint during the Olympics had less southwestern and southeastern origins. The latter were the main emission sources over the North China Plain. Episode 1 (23-28 July) was persistently dominated by CTs 8 and 5 and had more air masses with southwestern origins and shorter transport distances; episode 2 (4-8 August) had more air masses with southeastern origins and faster transport speeds. These results suggest that synoptic-scale circulation features are one of the primary drivers of day-to-day pollutant concentrations in and around Beijing, and that during the Olympics, circulation types favorable for dispersion and wet scavenging contributed significantly to the improvement in air quality.

Quantitative analysis of the impacts of synoptic circulation and emission reduction on air quality during the Beijing 


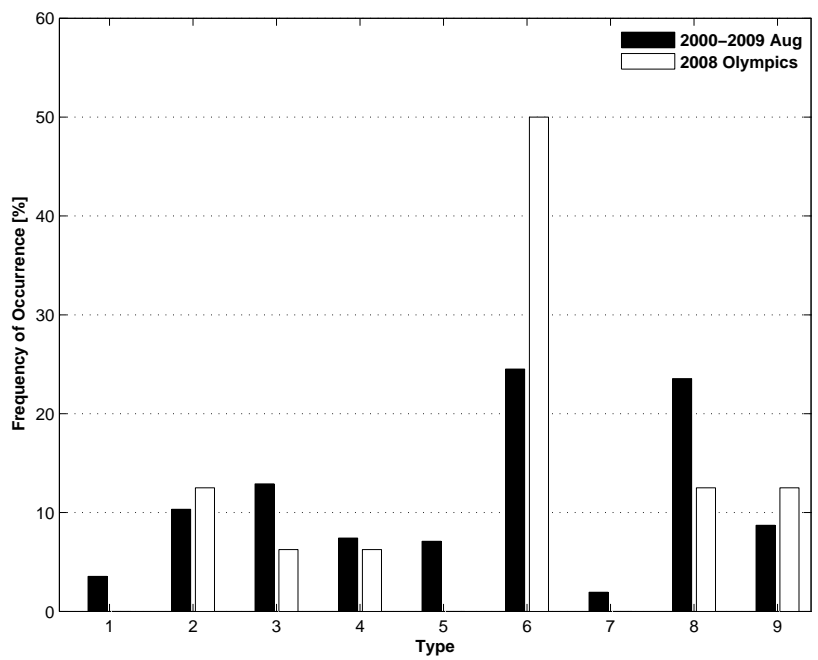

Fig. 12. Occurrence frequency by circulation type during the period of the Olympics and in August 2000-2009.

Olympics is important and challenging. Here a circulationto-environment method is proposed to evaluate the effectiveness of weather pattern in changing air quality. The noncontrol mean (i.e. excluding the emission control period) values of variables indicating air quality (e.g. visibility) were calculated for this analysis. The relationships between CTs and air quality parameters in the same season were assumed to be constant in different years. For the Olympics period (9-24 August 2008), we defined the total anomaly $\left(V^{\prime}\right)$ as the deviations in variables from their non-control means $(\bar{V})$ (summer during 205-2009 excluding the emission control period). This total anomaly in the Olympics was a composite anomaly due to the effects of both meteorology and emission reduction. The anomaly calculated from mean values in August 2005-2007 and 2009 for circulation types and the frequencies of circulation types during the Olympics can be considered to represent the change in visibility caused by the circulation patterns, not the emission reductions. We refer to this as the "circulation-driven" anomaly. The circulationdriven anomaly $\left(V c^{\prime}\right)$ was defined as $\sum_{i} f_{i} V_{i}-\bar{V}$, where $f_{i}$ is the frequency of occurrence of type-i circulation during a specific period and $V_{i}$ is the corresponding variable featuring that type. The relative contribution of synoptic circulation to air quality was then evaluated by the ratio of $V c^{\prime}$ to $V^{\prime}$. Figure 12 shows the $f_{i}$ value for each circulation type. The dominant CT during the Olympic Games was type 6. The results show that the contribution of the CT frequency anomaly during the Olympics to the increase in visibility was $54 \pm 25 \%$ (mean $\pm 1 \sigma$; the error calculation method is described in the Supplement S9). Using this method, the relative contribution of synoptic circulation to reducing $\mathrm{PM}_{10}$ and $\mathrm{BC}$ was estimated to be about $19 \pm 14 \%$ and $18 \pm 13 \%$, respectively. Performing the calculation again for non-control mean values of primary gaseous pollutants for the summer 2006-
2008, the contribution of synoptic circulation to reducing $\mathrm{SO}_{2}, \mathrm{NO}_{2}, \mathrm{NO}_{\mathrm{x}}$, and $\mathrm{CO}$ concentrations was estimated to be $41 \pm 36 \%, 12 \pm 7 \%, 10 \pm 5 \%$, and $19 \pm 11 \%$, respectively. Although large uncertainty was associated with the weather impact estimation due to the limitation of the gaseous pollutants data length and the variations of the emission rate, the results still demonstrated the advantageous conditions of synoptic-scale weather during the Olympics.

We have presented the first quantitative estimations of meteorological effects on more comprehensive air quality parameters (optical air quality, aerosol loadings, and primary gaseous pollutants mixing ratio) during the 2008 Olympics based on a synoptic circulation typing method. The synoptic circulation classification allows for integrated evaluation of the effects of numerous interrelated meteorological parameters and transport paths on air quality. Our results suggest the anomaly of CT could partly explain the reduction of air pollutant, and emission control as well as synoptic-scale circulation have contributed to the improvement of air quality during the Olympics.

\section{Conclusions, discussions and future research}

\subsection{Conclusions}

In this study we investigated the relationship between circulation pattern and air quality in Beijing and its surroundings using a synopitc approach. The prevailing circulation patterns were identified for the North China region using an objective classification procedure. The circulation types were analyzed in relation to the local meteorological conditions, transport pathways, and air quality parameters. The plume trajectories for each circulation type were calculated using backward integration of the Lagrangian dispersion model. The data used in this study included measurements at urban and rural sites and by satellite sensors. The main findings are as follow:

1. A set of nine daily circulation patterns were obtained for the North China region based on the 10-yr NCEP/NCAR SLP dataset using obliquely rotated Tmode PCA.

2. There was a significant difference in the local meteorology and footprints of 48-h backward trajectories among different circulation types. CT 1 (high pressure to west with strong pressure gradient) was characterized by northwestern origins and the fewest local and southeastern air mass sources. CT 6 (high pressure to northwest) showed air mass sources mostly from northern and eastern origins and had the second fewest local and southwestern sources. In contrast, CTs 5, 8, and 9 (weak pressure field, high pressure to the east, and low pressure to the northwest, respectively) were characterized by southern and southeastern trajectories, which 

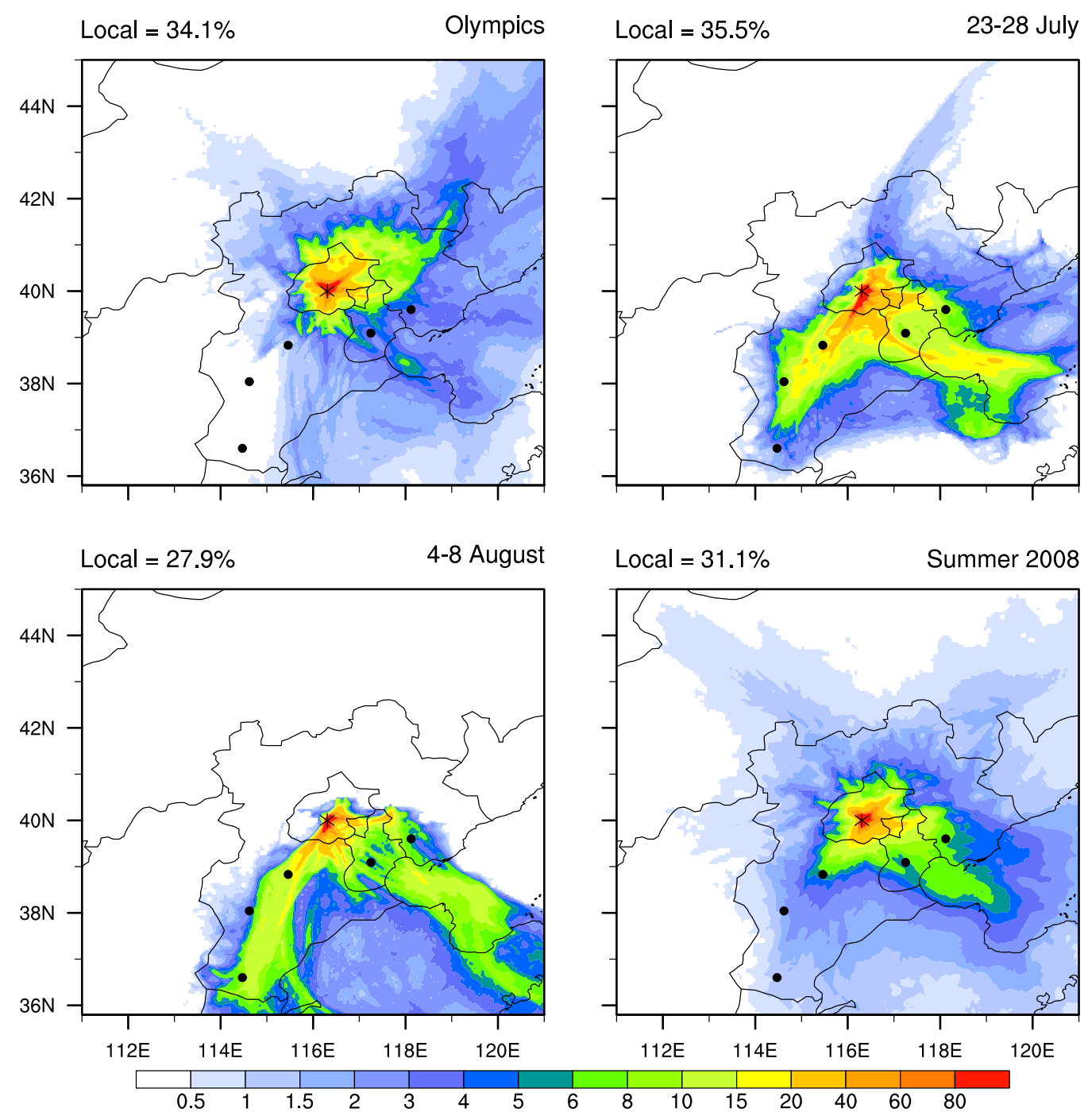

Fig. 13. Averaged footprints (residence times of 48-h backward trajectories) for four periods: the Olympics, two pollution episodes (23-28 July, 4-8 August), and the whole summer (June, July, August) of 2008. The black dots represent the loci of major cities in the North China Plain, as shown in Fig. 1. The PKU site is marked by an asterisk.

indicated a greater influence of highly polluting emission sources.

3. Poor air quality was mainly associated with three circulation patterns: "weak pressure field", "high pressure to east", and "low pressre to northwest" (found in CTs 5, 8, and 9). Clean air quality was associated with the CTs 1 and 6 . The different circulation types influenced air quality through transport pathways and local meteorological conditions. The average visibilities (with $\pm 1 \sigma$ ) in Beijing for CTs 1 and 6 during 2000-2009 were $18.5 \pm 8.3 \mathrm{~km}$ and $14.3 \pm 8.5 \mathrm{~km}$, respectively. CTs 5,8 , and 9 were characterized with poor visibilities of $6.0 \pm 3.5 \mathrm{~km}, 6.6 \pm 3.7 \mathrm{~km}$, and $6.7 \pm 3.6 \mathrm{~km}$, respectively. The mean concentrations of $\mathrm{PM}_{10}$ for CTs $1,6,5,8$, and 9 during 20052009 were $90.3 \pm 76.3 \mu \mathrm{g} \mathrm{m}^{-3}, \quad 111.7 \pm 89.6 \mathrm{\mu g} \mathrm{m}^{-3}$, $173.4 \pm 105.8 \mu \mathrm{g} \mathrm{m}^{-3}, \quad 158.4 \pm 90.0 \mu \mathrm{g} \mathrm{m}^{-3}, \quad$ and

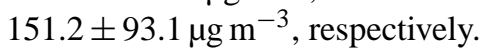

4. Analysis of the relationship between circulation pattern and air quality during the emission control period showed that synoptic-scale circulations were the primary drivers of day-to-day variations in pollutant concentration over Beijing and its surroundings. During the 2008 Summer Olympics, the frequency of CT 6, which is associated with good air quality, doubled compared with the frequency in the same season from 2000 to 2009. In addition, the footprints maps demonstrated a significantly decreased frequency of air masses that 
originated from the southern polluted region during the Olympics.

5. Using circulation-to-environment methods, the effectiveness of synoptic circulation in decreasing $\mathrm{PM}_{10}$, $\mathrm{BC}, \mathrm{SO}_{2}, \mathrm{NO}_{2}, \mathrm{NO}_{\mathrm{x}}, \mathrm{CO}$, and horizontal light extinction was estimated to be about $19 \pm 14 \%, 18 \pm 13 \%$, $41 \pm 36 \%, 12 \pm 7 \%, 10 \pm 5 \%, 19 \pm 11 \%$, and $54 \pm 25 \%$, respectively.

This work has established a long-term daily indices of synoptic-scale circulation types for the North China region and their relations to air quality in and around Beijing, with the understanding that synoptic-scale circulation drives the physical processes that control the accumulation, dispersion, and transport of air pollutants. We confirmed the advantageous synoptic weather conditions during the Olympics, and presented an integrated evaluation of the meteorological effects in improving air quality in Beijing. This is the first attempt to study the relationships between weather and air quality using an objective procedure of circulation classification in China. To further the understanding of the CTs associated with air quality, the characteristics of footprints for each CT were analyzed by high-resolution Lagrangian dispersion simulations. The results demonstrated that the circulation classification approach is not only capable of reflecting the impacts of local conditions linked to both air quality and local meteorology, but also provides a holistic assessment of the effect of synoptic circulation on regional pollutant concentration and transport pathways. This approach and the established correlations could also be useful for developing an operational forecast and warning system and for examining the impacts of climate change on air pollution and human health.

\subsection{Discussions and future research}

One possible concern is the stability of the circulation classification (i.e. the degree of similarity of groupings based on temporal subsamples of data and on a slightly different grid; Huth et al., 2008). Since the good stability in time and space for T-mode PCA procedure has been presented in detailed comparison by Huth (1996b) and Huth et al. (2008), here we just briefly discuss the results of two sensitivity studies. We changed the predefined domain one degree to south in experiment 1, and used 06:00 UTC SLP as input data in experiment 2. The results show that major circulation patterns and their correlations to air quality (visibility as an example) do not change (Supplement Figs. S9-10); the best air quality was still associated with CT "high pressure to west-north with strong pressure gradient", while CTs "weak pressure field", "high pressure to east" and "low pressure to northwest" were related to very poor air quality.

From the source to the monitoring sites, the concentration levels of the observed air pollutants are controlled by emission strengths and the physical (e.g. transport, coagula- tion, wet/dry deposition) and chemical processes (non-linear transformation) along the transport paths. We assume that the importance of these processes in determining the concentrations of the air pollutants relies on the circulation patterns. Apparently, the established associations between CTs and air quality are the results of these physical and chemical processes. This study focus on the impact of circulation patterns on air quality and transport pathways. For this purpose, the WRF-Flexpart model has unique advantages (Fleming et al., 2012; J. C. Lin et al., 2011) over Eulerian models, and could well describe the characteristics of dispersion and transport that is the most important factors determining air pollutant concentration. However, incorporating the detail chemical and physical processes into the circulation analysis is still a challenge. It is our ongoing research objective to combine an Eulerian-based regional air quality model with Lagrangian dispersion models to investigate the chemical and physical processes associated with circulation patterns in detail.

An additional research need in this field is to quantitatively examine the transport patterns determined by the synoptic controlled circulation, and how this relates to air pollution formation at local and regional scales. It has been shown in several studies that the forming of convergence lines and recirculation of air masses can severely degrade air quality (e.g. de Foy et al., 2006; Levy et al., 2009). We are currently exploring a method based on Lagrangian dispersion calculation to analyze the wind convergence lines forming in North China Plain, and to examine how weather patterns control the formation of the convergence lines, and subsequently how the convergence lines impact on the regional transport of air pollutants.

\section{Supplementary material related to this article is available online at: http://www.atmos-chem-phys.net/12/5031/2012/ acp-12-5031-2012-supplement.pdf}

\begin{abstract}
Acknowledgements. This study as part of the Campaign of Atmospheric Research in Beijing and surrounding areas in 2008 is partially supported by the Chinese National Public Benefit Research Foundation of Meteorology (Grant GYHY201006011), the National Nature Science Foundation of China under Grant No. 40921160380, 40975059 and 41175020, and Beijing Environmental Protection Bureau (OITC-G08026056). The authors thank the team of the CARE-Beijing field campaign. AERONET data at IAP and $\mathrm{XH}$ sites are used in this study, and we thank the PIs Pucai Wang and Hongbin Chen for their effort in establishing and maintaining the sites. The authors also acknowledge the editor and two anonymous reviewers whose valuable comments and suggestions significantly improved this article.
\end{abstract}

Edited by: M. Gauss 


\section{References}

Aiken, A. C., de Foy, B., Wiedinmyer, C., DeCarlo, P. F., Ulbrich, I. M., Wehrli, M. N., Szidat, S., Prevot, A. S. H., Noda, J., Wacker, L., Volkamer, R., Fortner, E., Wang, J., Laskin, A., Shutthanandan, V., Zheng, J., Zhang, R., Paredes-Miranda, G., Arnott, W. P., Molina, L. T., Sosa, G., Querol, X., and Jimenez, J. L.: Mexico city aerosol analysis during MILAGRO using high resolution aerosol mass spectrometry at the urban supersite (T0) Part 2: Analysis of the biomass burning contribution and the non-fossil carbon fraction, Atmos. Chem. Phys., 10, 5315-5341, doi:10.5194/acp-10-5315-2010, 2010.

An, X., Zhu, T., Wang, Z., Li, C., and Wang, Y.: A modeling analysis of a heavy air pollution episode occurred in Beijing, Atmos. Chem. Phys., 7, 3103-3114, doi:10.5194/acp-7-3103-2007, 2007.

Ashbaugh, L. L., Malm, W. C., and Sadeh, W. Z.: A residence time probability analysis of sulfur concentrations at Grand Canyon National Park, Atmos. Environ., 19, 1263-1270, 1985.

Atkinson, R. W., Fuller, G. W., Anderson, H. R., Harrison, R. M., and Armstrong, B.: Urban ambient particle metrics and health: a time-series analysis, Epidemiology, 21, 501-511, 2010.

Bardossy, A., Duckstein, L., and Bogardi, I.: Fuzzy rule based classification of atmospheric circulation patterns, Int. J. Climatol., 15, 1087-1097, 1995.

Bäumer, D., Vogel, B., Versick, S., Rinke, R., Möhler, O., and Schnaiter, M.: Relationship of visibility, aerosol optical thickness and aerosol size distribution in an ageing air mass over SouthWest Germany, Atmos. Environ., 42, 989-998, 2008.

Bernaards, C. A. and Jennrich, R. I.: Gradient projection algorithms and software for arbitrary rotation criteria in factor analysis, Educ. Psychol. Meas., 65, 770-790, 2005.

Brinkmann, W.: Application of non-hierarchically clustered circulation components to surface weather conditions: Lake Superior Basin winter temperatures, Theor. Appl. Climatol., 63, 41-56, 1999.

Cavazos, T.: Using self-organizing maps to investigate extreme climate events: an application to wintertime precipitation in the Balkans, J. Climate, 13, 1718-1732, 2000.

Chan, C. K. and Yao, X.: Air pollution in mega cities in China, Atmos. Environ., 42, 1-42, 2008.

Chen, D. S., Cheng, S. Y., Liu, L., Chen, T., and Guo, X. R.: An integrated MM5-CMAQ modeling approach for assessing transboundary PM10 contribution to the host city of 2008 Olympic summer games-Beijing, China, Atmos. Environ., 41, 1237-1250, doi:10.1016/j.atmosenv.2006.09.045, 2007.

Chen, F., Tewari, M., Kusaka, H., and Warner, T.: Current status of urban modeling in the community Weather Research and Forecast (WRF) model, paper presented at Joint Session with Sixth Symposium on the Urban Environment and AMS Forum: Managing our Physical and Natural Resources: Successes and Challenges, the 86th AMS Annual Meeting, AMS, Atlanta, Georgia, 28 January-3 February, 2006.

Cheng, W. L., Pai, J. L., Tsuang, B. J., and Chen, C. L.: Synoptic patterns in relation to ozone concentrations in West-Central Taiwan, Meteorol. Atmos. Phys., 78, 11-21, 2001.

Cheng, X. and Wallace, J. M.: Cluster analysis of the Northern Hemisphere wintertime 500-hPa height field: spatial patterns, J. Atmos. Sci., 50, 2674-2696, 1993.
Cheng, Y. F., Heintzenberg, J., Wehner, B., Wu, Z. J., Su, H., Hu, M., and Mao, J. T.: Traffic restrictions in Beijing during the Sino-African Summit 2006: aerosol size distribution and visibility compared to long-term in situ observations, Atmos. Chem. Phys., 8, 7583-7594, doi:10.5194/acp-8-7583-2008, 2008.

Chen, Z., Cheng, S., Li, J., Guo, X., Wang, W., and Chen, D.: Relationship between atmospheric pollution processes and synoptic pressure patterns in Northern China, Atmos. Environ., 42, 60786087, 2008.

Chou, C. C. K., Tsai, C.-Y., Shiu, C.-J., Liu, S. C., and Zhu, T.: Measurement of $\mathrm{NO}_{\mathrm{y}}$ during Campaign of Air Quality Research in Beijing 2006 (CAREBeijing-2006): Implications for the ozone production efficiency of $\mathrm{NO}_{\mathrm{x}}$, J. Geophys. Res., 114, D00G01, doi:10.1029/2008jd010446, 2009.

Chou, C. C.-K., Tsai, C.-Y., Chang, C.-C., Lin, P.-H., Liu, S. C., and Zhu, T.: Photochemical production of ozone in Beijing during the 2008 Olympic Games, Atmos. Chem. Phys., 11, 9825-9837, doi:10.5194/acp-11-9825-2011, 2011.

Chu, D. A., Kaufman, Y. J., Zibordi, G., Chern, J. D., Mao, J., Li, C., and Holben, B. N.: Global monitoring of air pollution over land from the Earth Observing System-Terra Moderate Resolution Imaging Spectroradiometer (MODIS), J. Geophys. Res., 108, 4661, doi:10.1029/2002jd003179, 2003.

Compagnucci, R. H. and Richman, M. B.: Can principal component analysis provide atmospheric circulation or teleconnection patterns?, Int. J. Climatol., 28, 703-726, 2008.

Comrie, A. C. and Yarnal, B.: Relationships between synoptic-scale atmospheric circulation and ozone concentrations in metropolitan Pittsburgh, Pennsylvania, Atmos. Environ., 26, 301-312, 1992.

de Foy, B., Clappier, A., Molina, L. T., and Molina, M. J.: Distinct wind convergence patterns in the Mexico City basin due to the interaction of the gap winds with the synoptic flow, Atmos. Chem. Phys., 6, 1249-1265, doi:10.5194/acp-6-1249-2006, 2006.

de Foy, B., Zavala, M., Bei, N., and Molina, L. T.: Evaluation of WRF mesoscale simulations and particle trajectory analysis for the MILAGRO field campaign, Atmos. Chem. Phys., 9, 44194438, doi:10.5194/acp-9-4419-2009, 2009.

de Foy, B., Burton, S. P., Ferrare, R. A., Hostetler, C. A., Hair, J. W., Wiedinmyer, C., and Molina, L. T.: Aerosol plume transport and transformation in high spectral resolution lidar measurements and WRF-Flexpart simulations during the MILAGRO Field Campaign, Atmos. Chem. Phys., 11, 3543-3563, doi:10.5194/acp-11-3543-2011, 2011.

Dockery, D. W. and Pope, C. A.: Acute respiratory effects of particulate air pollution, Annu. Rev. Publ. Health, 15, 107-132, 1994.

Downs, S. H., Schindler, C., Liu, L. J. S., Keidel, D., BayerOglesby, L., Brutsche, M. H., Gerbase, M. W., Keller, R., Kunzli, N., and Leuenberger, P.: Reduced exposure to $\mathrm{PM}_{10}$ and attenuated age-related decline in lung function, New Engl. J. Med., 357, 2338-2347, 2007.

Dudhia, J.: Numerical study of convection observed during the winter monsoon experiment using a mesoscale two-dimensional model, J. Atmos. Sci., 46, 3077-3107, 1989.

Eck, T., Holben, B., Reid, J., Dubovik, O., Smirnov, A., O'neill, N., Slutsker, I., and Kinne, S.: Wavelength dependence of the optical depth of biomass burning, urban, and desert dust aerosols, J. Geophys. Res., 104, 31333-31349, 1999. 
Engel-Cox, J. A., Holloman, C. H., Coutant, B. W., and Hoff, R. M.: Qualitative and quantitative evaluation of MODIS satellite sensor data for regional and urban scale air quality, Atmos. Environ., 38, 2495-2509, 2004.

Fang, M., Chan, C. K., and Yao, X.: Managing air quality in a rapidly developing nation: China, Atmos. Environ., 43, 79-86, 2009.

Fast, J. D. and Easter, R. C.: A Lagrangian particle dispersion model compatible with WRF, in: 7th WRF User's Workshop, NCAR, P6-02, 19-22 June, Boulder, Colorado, 2006.

Fleming, Z. L., Monks, P. S., and Manning, A. J.: Review: Untangling the influence of air-mass history in interpreting observed atmospheric composition, Atmos. Res., 104, 1-39, 2012.

Gao, Y., Liu, X., Zhao, C., and Zhang, M.: Emission controls versus meteorological conditions in determining aerosol concentrations in Beijing during the 2008 Olympic Games, Atmos. Chem. Phys., 11, 12437-12451, doi:10.5194/acp-11-12437-2011, 2011.

Gong, X. and Richman, M. B.: On the application of cluster analysis to growing season precipitation data in North America east of the Rockies, J. Climate, 8, 897-931, 1995.

He, Q., Li, C., Tang, X., Li, H., Geng, F., and Wu, Y.: Validation of MODIS derived aerosol optical depth over the Yangtze River Delta in China, Remote Sens. Environ., 114, 1649-1661, 2010.

He, X., Li, C. C., Lau, A. K. H., Deng, Z. Z., Mao, J. T., Wang, M. H., and Liu, X. Y.: An intensive study of aerosol optical properties in Beijing urban area, Atmos. Chem. Phys., 9, 8903-8915, doi:10.5194/acp-9-8903-2009, 2009.

Hewitson, B. and Crane, R.: Self-organizing maps: applications to synoptic climatology, Clim. Res., 22, 13-26, 2002.

Highwood, E. J. and Kinnersley, R. P.: When smoke gets in our eyes: the multiple impacts of atmospheric black carbon on climate, air quality and health, Environ. Int., 32, 560-566, 2006.

Holben, B., Eck, T., Slutsker, I., Tanre, D., Buis, J., Setzer, A., Vermote, E., Reagan, J., Kaufman, Y., and Nakajima, T.: AERONET - A federated instrument network and data archive for aerosol characterization, Remote Sens. Environ., 66, 1-16, 1998.

Hong, S. Y., Dudhia, J., and Chen, S. H.: A revised approach to ice microphysical processes for the bulk parameterization of clouds and precipitation, Mon. Weather Rev., 132, 103-120, 2004.

Huth, R.: An example of using obliquely rotated principal components to detect circulation types over Europe, Meteorol. Z., 2, 285-293, 1993.

Huth, R.: Properties of the circulation classification scheme based on the rotated principal component analysis, Meteorol. Atmos. Phys., 59, 217-233, 1996a.

Huth, R.: An intercomparison of computer-assisted circulation classification methods, Int. J. Climatol., 16, 893-922, 1996b.

Huth, R.: A circulation classification scheme applicable in GCM studies, Theor. Appl. Climatol., 67, 1-18, 2000.

Huth, R., Beck, C., Philipp, A., Demuzere, M., Ustrnul, Z., Cahynová, M., Kyselý, J., and Tveito, O. E.: Classifications of atmospheric circulation patterns, Ann. NY Acad. Sci., 1146, 105$152,2008$.

Jacobeit, J.: Classifications in climate research, Phys. Chem. Earth, 35, 411-421, 2010.

Janjić, Z. I.: Nonsingular implementation of the Mellor-Yamada level 2.5 scheme in the NCEP Meso model, Office Note \#437, National Center for Environmental Prediction, 2001.
Jansen, K. L., Larson, T. V., Koenig, J. Q., Mar, T. F., Fields, C., Stewart, J., and Lippmann, M.: Associations between health effects and particulate matter and black carbon in subjects with respiratory disease, Environ. Health Persp., 113, 1741-1746, 2005.

Jiang, N., Hay, J., and Fisher, G.: Synoptic weather types and morning rush hour nitrogen oxides concentrations during Auckland winters, Weather Clim., 25, 43-69, 2005.

Jiménez, P. A., González-Rouco, J. F., García-Bustamante, E., Navarro, J., Montávez, J. P., de Arellano, J. V.-G., Dudhia, J., and Muñoz-Roldan, A.: Surface Wind Regionalization over Complex Terrain: Evaluation and Analysis of a HighResolution WRF Simulation, J. Appl. Meteorol. Clim., 49, 268287, doi:10.1175/2009jamc2175.1, 2010.

Jiménez, P., González-Rouco, J., Montávez, J., García-Bustamante, E., Navarro, J., and Dudhia, J.: Analysis of the long-term surface wind variability over complex terrain using a high spatial resolution WRF simulation, Clim. Dyn., 1-14, 2012.

Kahl, J. D. and Samson, P. J.: Uncertainty in trajectory calculations due to low resolution meteorological data, J. Clim. Appl. Meteorol., 25, 1816-1831, 1986.

Kain, J. S.: The Kain Fritsch convective parameterization: an update, J. Appl. Meteorol., 43, 170-181, 2004.

Kalkstein, L. S. and Corrigan, P.: A synoptic climatological approach for geographical analysis: assessment of sulfur dioxide concentrations, Ann. Assoc. Am. Geograph., 76, 381-395, 1986.

Kaufman, Y. J. and Tanré, D.: Algorithm for remote sensing of tropospheric aerosol from MODIS, NASA MODIS Algorithm Theoretical Basis Document, Goddard Space Flight Center, 85, 1998.

Levy, I., Mahrer, Y., and Dayan, U.: Coastal and synoptic recirculation affecting air pollutants dispersion: A numerical study, Atmos. Environ., 43, 1991, 2009.

Levy, R., Remer, L., Martins, J., Kaufman, Y., Plana-Fattori, A., Redemann, J., and Wenny, B.: Evaluation of the MODIS aerosol retrievals over ocean and land during CLAMS, J. Atmos. Sci., 62, 974-992, 2005.

Li, B., Yuan, H., Feng, N., and Tao, S.: Comparing MODIS and AERONET aerosol optical depth over China, Int. J. Remote Sens., 30, 6519-6529, 2009.

Li, C., Mao, J., Lau, A., Yuan, Z., Wang, M., and Liu, X.: Application of MODIS satellite products to the air pollution research in Beijing, Sci. China Ser. D, 48, 209-219, 2005.

Li, P., Li, X., Yang, C., Wang, X., Chen, J., and Collett, J. L.: Fog water chemistry in Shanghai, Atmos. Environ., 45, 4034, 2011.

Lin, J. C., Brunner, D., and Gerbig, C.: Studying atmospheric transport through Lagrangian models, Eos Trans. AGU, 92, doi:10.1029/2011eo210001, 2011.Liu, P., Zhao, C., Zhang, Q., Deng, Z., Huang, M., Ma, X., and Tie, X.: Aircraft study of aerosol vertical distributions over Beijing and their optical properties, Tellus B, 61, 756-767, doi:10.1111/j.16000889.2009.00440.x, 2009.

Lin, W., Zhu, T., Huang, W., Hu, M., Brunekreef, B., Zhang, Y., Liu, X., Cheng, H., Gehring, U., Li, C., and Tang, X.: Acute respiratory inflammation in children and black carbon in ambient air before and during the 2008 Beijing Olympics, Environ. Health Persp., 119, 1507-1512, doi:10.1289/ehp.1103461, 2011.

Liu, P., Zhao, C., Zhang, Q., Deng, Z., Huang, M., Ma, X., and Tie, X.: Aircraft study of aerosol vertical distributions over Beijing and their optical properties, Tellus B, 61, 756-767, doi:10.1111/j.1600-0889.2009.00440.x, 2009. 
Liu, P., Zhao, C., Göbel, T., Hallbauer, E., Nowak, A., Ran, L., Xu, W., Deng, Z., Ma, N., and Mildenberger, K.: Hygroscopic properties of aerosol particles at high relative humidity and their diurnal variations in the North China Plain, Atmos. Chem. Phys, 11, 3479-3494, 2011.

Lo, J. C.-F., Yang, Z.-L., and Pielke, R. A., Sr.: Assessment of three dynamical climate downscaling methods using the Weather Research and Forecasting (WRF) model, J. Geophys. Res., 113, D09112, doi:10.1029/2007jd009216, 2008.

Lund, I.: Map-pattern classification by statistical techniques, J. Appl. Meteorol., 2, 56-65, 1963.

Magari, S. R., Hauser, R., Schwartz, J., Williams, P. L., Smith, T. J., and Christiani, D. C.: Association of heart rate variability with occupational and environmental exposure to particulate air pollution, Circulation, 104, 986, 2001.

McGregor, G. R. and Bamzelis, D.: Synoptic typing and its application to the investigation of weather air pollution relationships, Birmingham, United Kingdom, Theor. Appl. Climatol., 51, 223236, 1995.

Mijling, B.: Reductions of $\mathrm{NO}_{2}$ detected from space during the 2008 Beijing Olympic Games, Geophys. Res. Lett., 36, L13801, doi:10.1029/2009GL038943, 2009.

Molina, M. J. and Molina, L. T.: Megacities and atmospheric pollution, J. Air Waste Manage. Assoc, 54, 644-680, 2004.

Mlawer, E. J., Taubman, S. J., Brown, P. D., Iacono, M. J., and Clough, S. A.: Radiative transfer for inhomogeneous atmospheres: RRTM, a validated correlated-k model for the longwave, J. Geophys. Res., 102, 16663-16682, doi:10.1029/97JD00237, 1997.

Müller, G. V., Compagnucci, R., Nuñez, M. N., and Salles, A.: Surface circulation associated with frost in the wet pampas, Int. J. Climatol., 23, 943-961, 2003.

Pagano, L. E., Sims, A. P., and Boyles, R. P.: A comparative study between FLEXPART-WRF and HYSPLIT in an operational setting: analysis of fire emissions across complex geography using WRF, M.Sc. Thesis, North Carolina State University, Raleigh, North Carolina, 2010.

Pan, Z., Takle, E., Gutowski, W., and Turner, R.: Long Simulation of Regional Climate as a Sequence of Short Segments, Mon. Weather Rev., 127, 308-321, 1999.

Patel, M. M., Chillrud, S. N., Correa, J. C., Hazi, Y., Feinberg, M., Kc, D., Prakash, S., Ross, J. M., Levy, D., and Kinney, P. L.: Traffic-related particulate matter and acute respiratory symptoms among New York City Area adolescents, Environ. Health Persp., 118, 1338-1343, doi:10.1289/ehp.0901499, 2010.

Philipp, A., Bartholy, J., Beck, C., Erpicum, M., Esteban, P., Fettweis, X., Huth, R., James, P., Jourdain, S., and Kreienkamp, F.: COST733CAT-a database of weather and circulation type classifications, Phys. Chem. Earth, 35, 360-373, 2010.

Pope Iii, C. A. and Dockery, D. W.: Health effects of fine particulate air pollution: lines that connect, J. Air Waste Manage., 56, 709$742,2006$.

Quan, J., Zhang, Q., He, H., Liu, J., Huang, M., and Jin, H.: Analysis of the formation of fog and haze in North China Plain (NCP), Atmos. Chem. Phys. Discuss., 11, 11911-11937, doi:10.5194/acpd-11-11911-2011, 2011.

Ramanathan, V. and Carmichael, G.: Global and regional climate changes due to black carbon, Nat. Geosci., 1, 221-227, 2008.
Richman, M. B.: Obliquely rotated principal components: an improved meteorological map typing technique?, J. Appl. Meteorol., 20, 1145-1159, 1981.

Shahgedanova, M., Burt, T., and Davies, T.: Synoptic climatology of air pollution in Moscow, Theor. Appl. Climatol., 61, 85-102, 1998.

Sloane, C. S.: Summertime visibility declines: meteorological influences, Atmos. Environ., 17, 763-774, 1983.

Sloane, C. S.: Meteorologically adjusted air quality trends: visibility, Atmos. Environ., 18, 1217-1229, 1984.

Smirnov, A., Holben, B., Eck, T., Dubovik, O., and Slutsker, I.: Cloud-screening and quality control algorithms for the AERONET database, Remote Sens. Environ., 73, 337-349, 2000.

Stohl, A.: Computation, accuracy and applications of trajectories a review and bibliography, Atmos. Environ., 32, 947-966, 1998.

Stohl, A., Hittenberger, M., and Wotawa, G.: Validation of the Lagrangian particle dispersion model FLEXPART against largescale tracer experiment data, Atmos. Environ., 32, 4245-4264, 1998.

Stohl, A., Forster, C., Frank, A., Seibert, P., and Wotawa, G.: Technical note: The Lagrangian particle dispersion model FLEXPART version 6.2, Atmos. Chem. Phys., 5, 2461-2474, doi:10.5194/acp-5-2461-2005, 2005.

Sun, Y., Wang, Y., and Zhang, C.: Vertical observations and analysis of $\mathrm{PM}_{2.5}, \mathrm{O}_{3}$, and $\mathrm{NO}_{\mathrm{x}}$ at Beijing and Tianjin from towers during summer and autumn 2006, Adv. Atmos. Sci., 27, 123-136, 2010.

Tang, G., Li, X., Wang, Y., Xin, J., and Ren, X.: Surface ozone trend details and interpretations in Beijing, 2001-2006, Atmos. Chem. Phys., 9, 8813-8823, doi:10.5194/acp-9-8813-2009, 2009.

Vucetic, S., Han, B., Mi, W., Li, Z., and Obradovic, Z.: A DataMining Approach for the Validation of Aerosol Retrievals, Geosci. Remote Sens. Lett., IEEE, 5, 113-117, 2008.

Wang, B., Shao, M., Lu, S. H., Yuan, B., Zhao, Y., Wang, M., Zhang, S. Q., and Wu, D.: Variation of ambient non-methane hydrocarbons in Beijing city in summer 2008, Atmos. Chem. Phys., 10, 5911-5923, doi:10.5194/acp-10-5911-2010, 2010.

Wang, C.: A modeling study on the climate impacts of black carbon aerosols, J. Geophys. Res., 109, D03106, doi:10.1029/2003jd004084, 2004.

Wang, M., Zhu, T., Zheng, J., Zhang, R. Y., Zhang, S. Q., Xie, X. X., Han, Y. Q., and Li, Y.: Use of a mobile laboratory to evaluate changes in on-road air pollutants during the Beijing 2008 Summer Olympics, Atmos. Chem. Phys., 9, 8247-8263, doi:10.5194/acp-9-8247-2009, 2009.

Wang, M., Zhu, T., Zhang, J. P., Zhang, Q. H., Lin, W. W., Li, Y., and Wang, Z. F.: Using a mobile laboratory to characterize the distribution and transport of sulfur dioxide in and around Beijing, Atmos. Chem. Phys., 11, 11631-11645, doi:10.5194/acp11-11631-2011, 2011.

Wang, S., Zhang, J., Zeng, X., Zeng, Y., Wang, S., and Chen, S.: Association of traffic-related air pollution with children's neurobehavioral functions in Quanzhou, China, Environ. Health Persp., 117, 1612-1618, doi:10.1289/ehp.0800023, 2009.

Wang, S., Zhao, M., Xing, J., Wu, Y., Zhou, Y., Lei, Y., He, K., $\mathrm{Fu}$, L., and Hao, J.: Quantifying the air pollutants emission reduction during the 2008 Olympic Games in Beijing, Environ. Sci. Technol., 44, 2490-2496, 2010. 
Wang, T., Nie, W., Gao, J., Xue, L. K., Gao, X. M., Wang, X. F., Qiu, J., Poon, C. N., Meinardi, S., Blake, D., Wang, S. L., Ding, A. J., Chai, F. H., Zhang, Q. Z., and Wang, W. X.: Air quality during the 2008 Beijing Olympics: secondary pollutants and regional impact, Atmos. Chem. Phys., 10, 7603-7615, doi:10.5194/acp-10-7603-2010, 2010.

Wang, Y., Hao, J., McElroy, M. B., Munger, J. W., Ma, H., Chen, D., and Nielsen, C. P.: Ozone air quality during the 2008 Beijing Olympics: effectiveness of emission restrictions, Atmos. Chem. Phys., 9, 5237-5251, doi:10.5194/acp-9-5237-2009, 2009.

Wang, Y., Konopka, P., Liu, Y., Chen, H., Müller, R., Plöger, F., Riese, M., Cai, Z., and Lü, D.: Tropospheric ozone trend over Beijing from 2002-2010: ozonesonde measurements and modeling analysis, Atmos. Chem. Phys. Discuss., 12, 11175-11199, doi:10.5194/acpd-12-11175-2012, 2012.

Wehner, B., Birmili, W., Ditas, F., Wu, Z., Hu, M., Liu, X., Mao, J., Sugimoto, N., and Wiedensohler, A.: Relationships between submicrometer particulate air pollution and air mass history in Beijing, China, 2004-2006, Atmos. Chem. Phys., 8, 6155-6168, doi:10.5194/acp-8-6155-2008, 2008.

Wei, P., Cheng, S., Li, J., and Su, F.: Impact of boundary-layer anticyclonic weather system on regional air quality, Atmos. Environ., 45, 2453-2463, doi:10.1016/j.atmosenv.2011.01.045, 2011.

Witte, J., Schoeberl, M., Douglass, A., Gleason, J., Krotkov, N., Gille, J., Pickering, K., and Livesey, N.: Satellite observations of changes in air quality during the 2008 Beijing Olympics and Paralympics, Geophys. Res. Lett., 36, L17803, doi:10.1029/2009g1039236, 2009.
Xia, X., Chen, H., Wang, P., Zhang, W., Goloub, P., Chatenet, B., Eck, T., and Holben, B.: Variation of column-integrated aerosol properties in a Chinese urban region, J. Geophys. Res., 111, D05204, doi:10.1029/2005JD006203, 2006.

Yarnal, B.: Synoptic climatology in environmental analysis: a primer, Belhaven Press, London, 1993.

Žagar, N., Žagar, M., Cedilnik, J., Gregoričc, G., and Rakovec, J.: Validation of mesoscale low-level winds obtained by dynamical downscaling of ERA40 over complex terrain, Tellus A, 58, 445455, doi:10.1111/j.1600-0870.2006.00186.x, 2006.

Zhang, Q. H., Zhang, J. P., and Xue, H. W.: The challenge of improving visibility in Beijing, Atmos. Chem. Phys., 10, 78217827, doi:10.5194/acp-10-7821-2010, 2010.

Zhang, Q., Streets, D. G., Carmichael, G. R., He, K. B., Huo, H., Kannari, A., Klimont, Z., Park, I. S., Reddy, S., Fu, J. S., Chen, D., Duan, L., Lei, Y., Wang, L. T., and Yao, Z. L.: Asian emissions in 2006 for the NASA INTEX-B mission, Atmos. Chem. Phys., 9, 5131-5153, doi:10.5194/acp-9-5131-2009, 2009.

Zhang, J., Mauzerall, D. L., Zhu, T., Liang, S., Ezzati, M., and Remais, J. V.: Environmental health in China: progress towards clean air and safe water, The Lancet, 375, 1110-1119, 2010.

Zhang, X., Wang, Y., Lin, W., Zhang, Y., Zhang, X., Zhao, P., Yang, Y., Wang, J., Hou, Q., and Che, H.: Changes of atmospheric composition and optical properties over BEIJING2008 Olympic monitoring campaign, B. Am. Meteorol. Soc., 90, 1633-1651, 2009.

Zhu, C., Wang, B., and Qian, W.: Why do dust storms decrease in northern China concurrently with the recent global warming?, Geophys. Res. Lett., 35, L18702, doi:10.1029/2008g1034886, 2008 . 